TAO, Vol. 13, No. 4, 417-448, December 2002

\title{
Numerical Simulations with MM5 3DVAR Initialization
}

\author{
Ching-Yuang Huang ${ }^{1, *}$, Ying-Hwa Kuo ${ }^{2}$, and Wei Huang ${ }^{2}$ \\ (Manuscript received 11 January 2002, in final form 22 August 2002)
}

\begin{abstract}
The recently developed MM5 three-dimensional variational (3DVAR) assimilation system at NCAR has been used to investigate influences of ingested sounding and ship observation data on numerical simulations of severe weather in the vicinity of Taiwan. Three weather events were simulated in this study, which include a Mei-Yu front in June 1998, Supertyphoon Bilis in August 2000 and Typhoon Nari in September 2001. For the MeiYu front, the simulated low-pressure system northeast of Taiwan is stronger when the 3DVAR is performed during initialization. The simulated patterns of heavy rainfall just off the southern tip of Taiwan are also closer to observations for the run with 3DVAR. For the second case of Typhoon Bilis, both runs with and without 3DVAR show a northward bias in track upstream of eastern Taiwan. However, due to Iess northward track deflection, the simulated heavy rainfall in Taiwan for the 3DVAR run is in better agreement with observations.

For the no-3DVAR run, the simulated Typhoon Nari consistently moves southwestward toward Taiwan but then makes an incorrect landfall at northwestern Taiwan. With 3DVAR, the track simulation is improved with a landfall position at northeastern Taiwan. During landfall, the associated cloud convection is enhanced as the intense vortex core is in confrontation with the leading edge of the Central Mountain Range (CMR) and its movement is slowed down along the northwestern coast. The combination of both compression and stagnation of the embedded convective system may explain the extremely intense rainfall in northern Taiwan. The feature of observed intense rainfall over the southwestern slope base of the CMR is also captured, but the intensity is considerably underpredicted due to lagging and weakening of the vortex core at later times for both runs with and without 3DVAR. The track simulation at later times has also been improved in the 3DVAR run, but the associated geometric distributions of 72$h$ accumulated rainfall amounts in general are similar to those without
\end{abstract}

\footnotetext{
${ }^{1}$ Department of Atmospheric Sciences, National Central University, Taiwan

${ }^{2}$ National Center for Atmospheric Research, USA

* Corresponding author address. Prof. Ching-Yuang Huang, Department of Atmospheric Sciences, National Central University, Chung-Li, Taiwan 32054; E-mail: hcy@atm.ncu.edu.tw
} 


\begin{abstract}
3DVAR. In the typhoon experiment with a bogus vortex, the 3DVAR run preserves the initial vortex intensity quite well. However, the rainfall and track simulations are not improved by the ingestion of the bogus vortex for both runs with and without 3DVAR.
\end{abstract}

(Key words: MMS 3DVAR, Typhoon Bilis, Typhoon Nari, Bogus vortex)

\title{
1. INTRODUCTION
}

Data assimilation (DA) has recently been recognized as a useful way of providing better "consistent" initial conditions for numerical weather prediction (NWP) in the meteorological community. One of the most atractive and effective methods for DA is based on the estimation theory that constructs a theoretical basis for variational analyses in minimization of the bias of analyzed data (Gelb 1980). This mathematical treatment, through the so-called Kalman filter, may provide a theoretically optimal solution for the data system to be analyzed (Zou et al. 1997). A full set of data in an all assimilation time window has beneficial impacts resulting from strong constraints upon the model integrated state with both physics and dynamics involved. This method using variational minimization for data given within a definite time window is termed 4DVAR. However, 4DVAR has been known to be very time-consuming due to the adjoint nature of model integration in iteratively searching for the optimal solution. Despite its complexities and heavy computational loads, 4DVAR by using the adjoint MM5 to assimilate rainfall and precipitable water (PW) data has been shown to be capable of improving quantitative prediction forecast (QPF) due to improved initial divergence and moisture conditions (Zou and Kuo 1996).

The degraded system of ADVAR is 3DVAR that utilizes observations as well as analyses near the current time (i.e. the "initial time"). Since both model integration and adjoint model integration are not needed in 3DVAR, it greatly simplifies the filtering processes with relatively cheaper adjoint operators for ingestion of various observations (Courtier et al. 1998; Rabier et al. 1997; Vandenberghe and Kuo 1999). Another advantage of 3DVAR, as compared to $4 \mathrm{DVAR}$, is at its mathematical configuration of multi-domains that facilitate nested simulations for phenomena on a smaller scale. With more and more unconventional data (including measurements from satellite, radar and other remote sensors), ingestion of these data into NWP models has been believed to be one of top priorities for improving on weather forecasts. In practice, whenever these data become available, they should be assimilated during their ingestion time window provided that their error covariance matrices have been well known. In this study, we utilize MM5 3DVAR to incorporate sounding observations with the diagonal error covariance matrix provided by NCEP for the operational Spectral Statistical Interpolation (SSI) 3DVAR system (Parrish and Derber 1992). This so-called NMC method has been implemented at several operation centers. Hollingworth and Loennberg (1986) and Loennberg and Hollingworth (1986) compared forecasts with observations to determine the structure of the background error covariance matrix in ECMWF 3DVAR system. The details of the MM5 3DVAR system regarding the observation and background error covariance ma- 
trices can be found in Vandenberghe and Kuo (1999).

The performance of MM5 3DVAR is being improved with more types of observations included. This paper is a preliminary investigation of the current MM5 3DVAR feasibility in incorporating conventional sounding and ship observations, despite that other types of observations can also be assimilated. Hence, this study is oriented to the assessments of initialization based on identical data sources used in different objective analysis schemes and the responses of model integration to 3DVAR increments. To provide a helpful reference for the performance of current MM5 3DVAR, three different cases (one Mei-Yu front case and two typhoon cases) will be simulated with particular emphasis on rainfall prediction in this paper. Numerical aspects, including model setups for simulation, will be introduced in section 2 . The model simulation results for the three chosen cases will be presented in section 3. A preliminary study on MM5 3DVAR in typhoon experiments with a bogus vortex has been conducted and the results will also be discussed in this section. Finally, concluding remarks are given in section 4.

\section{NUMERICAL ASPECTS}

\subsection{MM5 3DVAR}

The Kalman filter theoretically provides a minimization of an objective function (i.e. the cost function) defined as

$$
J=\frac{1}{2}\left\{\left(x-x_{b}\right)^{T} \mathbf{B}^{-1}\left(x-x_{b}\right)+\left[y_{o b s}-H(x)\right]^{T} \mathbf{O}^{-1}\left[y_{o b s}-H(x)\right]\right\},
$$

where

$x:$ analysis variable vector (n-dimensional),

$x_{b}$ : background variable vector (n-dimensional),

$y_{\text {obs }}:$ Gobservation vector (m-dimensional),

B: Gbackground error covariance matrix $(\mathrm{n} \times \mathrm{n})$,

O: Gobservation error covariance matrix $(\mathrm{m} \times \mathrm{m})$,

$\mathrm{H}$ : nonlinear operator to transform the analysis variable vector to the observation vector.

At the extreme, the derivative of $J$ would vanish, i.e.

$$
\nabla J=0=\mathbf{B}^{-1}\left(x-x_{b}\right)-\mathbf{H}^{T} \mathbf{O}^{-1}(y-\mathbf{H} x),
$$

and thus, $x_{a}$, the estimate of $x$, can be obtained as

$$
x_{a}=x_{b}+\left[\mathbf{B}^{-1}+\mathbf{H}^{T} \mathbf{O}^{-1} \mathbf{H}\right]^{-1} \mathbf{H}^{T} \mathbf{O}^{-1}\left(y-H x_{b}\right),
$$

where $\mathbf{H}=\partial H / \partial x$ is the tangent linear approximation of the nonlinear operator $H$. Due to the fact that the transformation operation may be highly nonlinear, an incremental formulation based on the above linearity is often used to obtain the solution. Preconditioning of the incremental formulation is also performed in order to avoid the inversion of the matrix $\mathbf{B}$ that in 
practice is rarely adopted. The details of the minimization procedure in MM5 3DVAR may be found in Vandenberghe and Kuo (1999).

In MM5 3DVAR, all observation errors are assumed to be uncorrelated in space and time so that the associated covariance matrix $\mathbf{O}$ is diagonal. The diagonal elements of the matrix $\mathrm{O}$ are prescribed as those used in the NCEP operational SSI 3DVAR (Parrish and Derber 1992) but with some correcting factors. Based on the tests with NCEP observational synoptic errors, it was found that temperature and relative humidity errors were usually over-estimated by NCEP. Two correcting factors of 0.5 and 0.25 therefore have been applied for temperature and relative humidity, respectively, in MM5 3DVAR. The background error covariance matrix $\mathbf{B}$ is prescribed as monthly mean forecast error variances derived from yearly NCAR MM5 forecast. The effect of spatial error correlations existing in $\mathbf{B}$ on the analysis vector then can be produced by a recursive filter (Lorenc 1992) with a correlation length of 10 model grid points. The background vector is given by previous forecast fields or first guesses from global model assimilation at the initial time. Hence, both influences of conventional sounding observations and model dynamics have been taken into functional analyses that render a minimization for the background information. Herein, 3DVAR would tend to further enhance the influences of ingested data on subsynoptic scale as compared to conventional objective analysis. As we will see, through global minimization of 3DVAR, such data ingestion at the initial time has beneficial impacts on weather simulation or forecast. The ingestion of satellite data (e.g. SSM/I observations) has not been considered in this study since it requires extensive error statistics for constructing the covariance matrix prior to model simulation.

\subsection{Simulation Setups}

Three cases are investigated in this study, which include a Mei-Yu front in June 1998, Supertyphoon Bilis in August 2000 and Typhoon Nari in September 2001. All the three cases have been simulated using MM5 version 3.4 with explicit treatment for ice/graupel physics in all the domains, Kuo's scheme and Grell's scheme for cumulus parameterization in domain 1 (largest) and domain 2 (second largest), respectively, and the Blackadar scheme for PBL parameterization in all the domains. A detailed description of MM5 is given by Dudhia (1993). Here is a brief summary of the model setups for the three cases:

Mei-Yu front case: Two domains ( 45 and $15 \mathrm{~km}$ resolutions), 72-h forecast.

Typhoon Bilis case: Three domains (45, 15 and $5 \mathrm{~km}$ (Resolutions), 36-h forecast (for one sensitivity run) or $60 \mathrm{~h}$ forecast (for the control run).

Typhoon Nari case: Three domains (45, 15 and $5 \mathrm{~km}$ resolutions), 72-h forecast.

In domain 3 with $5-\mathrm{km}$ resolution, the maximum resolved terrain height for the Central Mountain Range (CMR) in Taiwan (shown in Fig. 7b) is about $3 \mathrm{~km}$ and should be adequate for studying the interaction of the CMR and invading typhoons. Although MM5 3DVAR allows more nested grids, it appears to only pass information in coarser grids into finer grids as linear interpolation would result. Hence, $5-\mathrm{km}$ resolution may be enough for our purposes focusing on mesoscale weather evolution. All the three cases will be simulated with and without 3DVAR during initialization. In addition to the control runs for typhoon cases, sensi- 
tivity runs with a bogus vortex will be conducted to investigate the behaviors of model performance with and without 3DVAR modulation. All the simulations for the three cases have performed the MM5 objective module, LITTLE_R, to include sounding and ship observations that have also been used in NCEP global assimilated analyses as the first guesses. Hence, the initialization with 3DVAR may be regarded as enhancement of observational influences through the optimal Kalman filter.

\section{RESULTS}

\subsection{The Mei-Yu Front Case}

The first case involves a typical Mei-Yu front that migrated slowly offshore of southeastern China. The front was aligned roughly across central Taiwan at 0000 UTC 3 June 1998 with extension to southern Japan. A weak low was embedded in the front as can be seen in surface weather maps (figure not shown). The frontal structure of the near-surface wind in the vicinity of Taiwan is well captured in the model initial condition as shown in Fig. 1 for the run without 3DVAR. A low-pressure system was under development near the coastal region of northeastern Taiwan as the front was nearly stagnant in central Taiwan and was somewhat distorted 24 $\mathrm{h}$ later. This weak surface low then migrated northeastward toward Japan and developed into a prominent cut-off low-pressure system just southeast of Japan by $72 \mathrm{~h}$ (figure not shown). Compared with Fig. 1, the 3DVAR run has produced slightly stronger wind at the initial time (0000 UTC 3 June 1998) than the run without 3DVAR, particularly in the region northeast of Taiwan (Fig. 2). Although the initial discrepancies (Figs. 1a and 2a) for these two runs seem to be minor, the 3DVAR run has produced a deeper low just northeast of Taiwan at $24 \mathrm{~h}$ (Fig. 2b) and the low pressure is about $7 \mathrm{hPa}$ lower (Fig. 2c) than that without 3DVAR at $36 \mathrm{~h}$ (Fig. 1c). Both runs have exhibited considerably biased propagation of the low center at $72 \mathrm{~h}$, but their flow structures appear to be similar (figure not shown).

With stronger convergence, the flow for the 3DVAR run has produced considerably larger rainfall amounts in the fine domain (Fig. 2d). The major rainfall distribution just off southern Taiwan is mainly displayed east-westward for the 3DVAR run as compared to that roughly extends southwestward for the run without 3DVAR (Fig. 1d). The maximum amount of about $500 \mathrm{~mm}$ in $6 \mathrm{~h}$ associated with this rainfall activity is reasonable for the very strong flow convergence over the ocean; more than $90 \%$ of the total is found from stable precipitation resolved by the model grids. The rainfall pattern for the 3DVAR run appears to be more consistent with cloud imagery observations as shown in Fig. 3. The large differences in the rainfall distributions and intensities have revealed the sensitivity of model prediction to such small variations in the initial conditions.

To support more favorable performance by the 3DVAR run, the IR satellite images at 2133 UTC 3 and 0033 UTC 4 are shown in Fig. 3 for comparisons with the patterns of the simulated rainfall. The activities of cloud convection revealed by the IR images at these two times may indicate the patterns of 6-h accumulated rainfall amounts during 1800 UTC 3-0000 UTC 4 (Figs. 1d and 2d). As can be seen, a cloud cluster develops roughly in a line extending from the southern tip of Taiwan and appears to be coincident with the results for the 3DVAR 


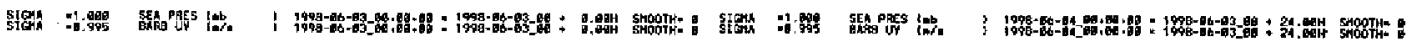
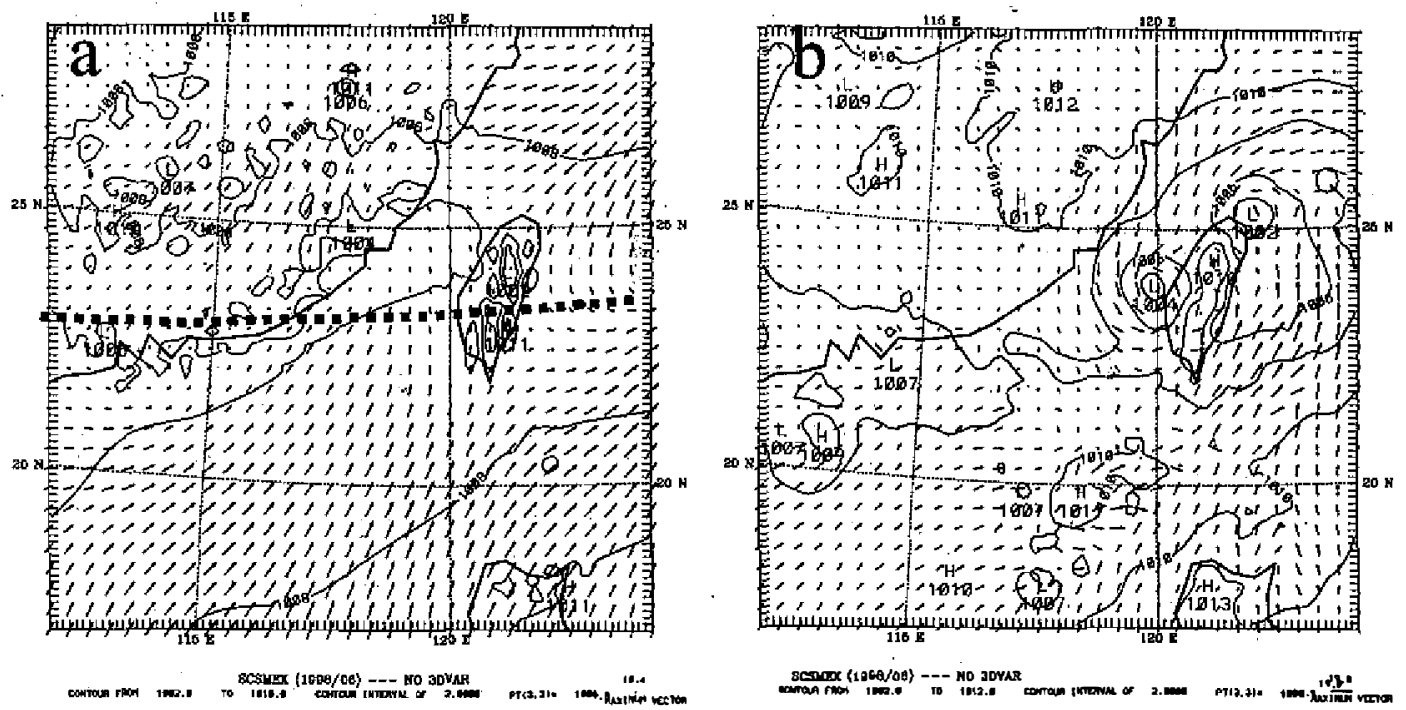

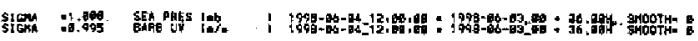
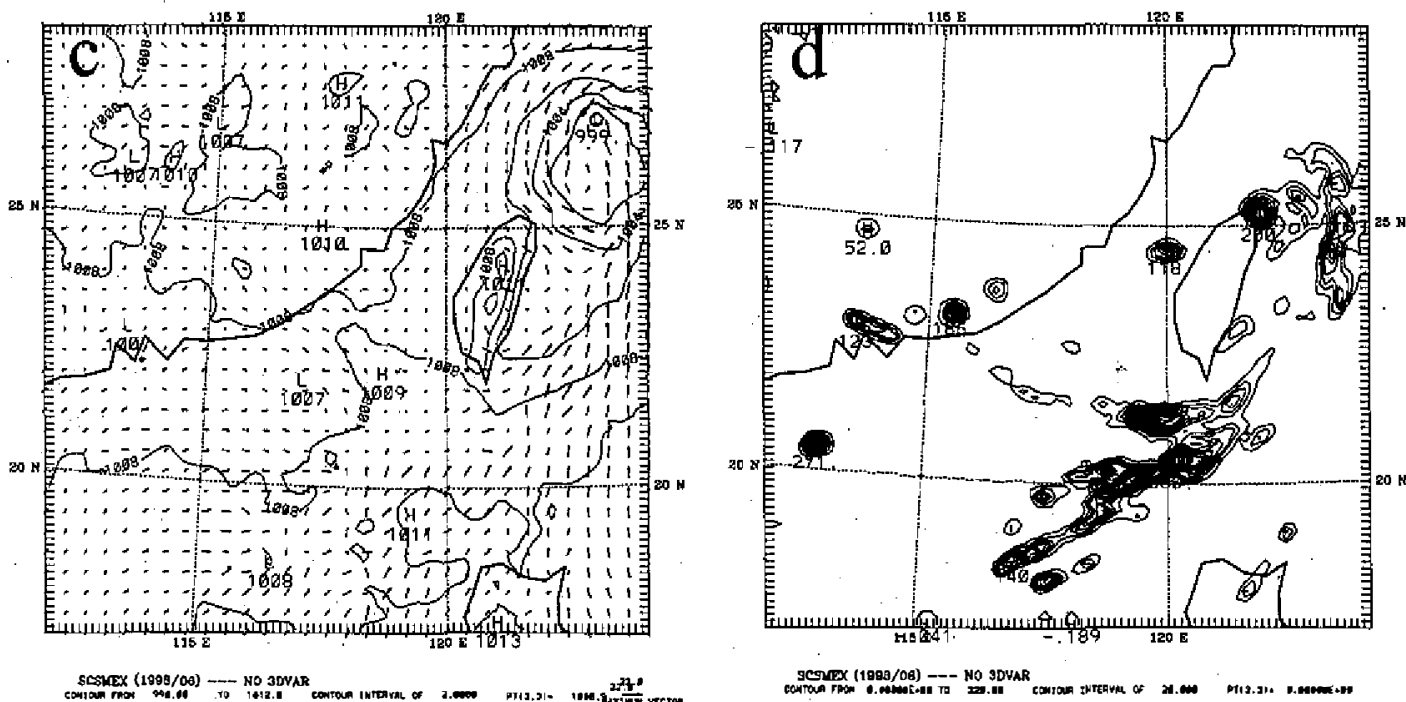

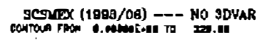

Fig. 1. The simulated sea-level pressure $(\mathrm{mb})$ and near-surface horizontal wind $\left(\mathrm{m} \mathrm{s}^{-1}\right)$ in the second domain 2 for the run without 3DVAR for the MeiYu front case in June 1998 at (a) the initial time (0000 UTC 3), (b) $24 \mathrm{~h}$ and (c) $36 \mathrm{~h}$. (d) for the 6-h accumulated rainfall amounts during 1800 UTC $3 \sim 0000$ UTC 4 with a contour interval of $20 \mathrm{~mm}$. The bold line in (a) indicates the geometric positions of the surface front. 


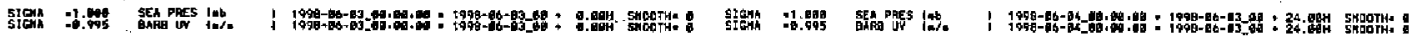
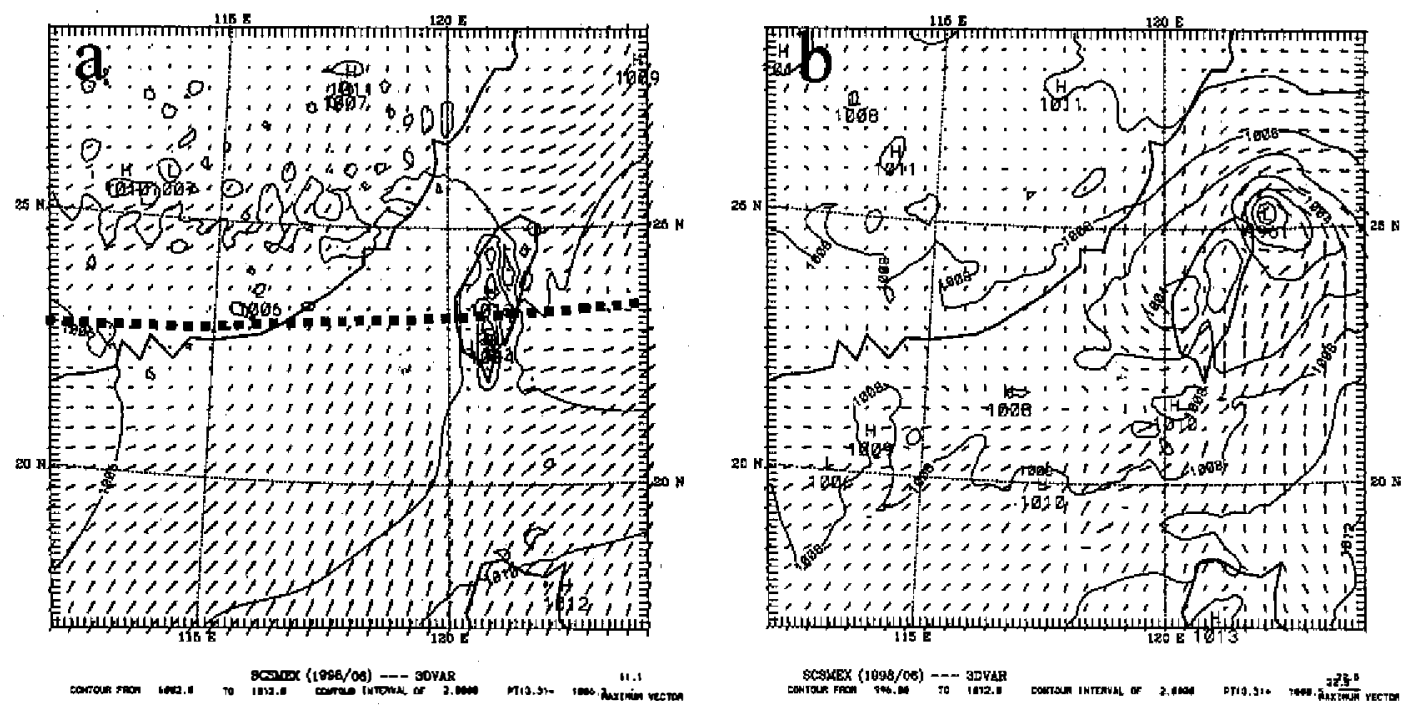

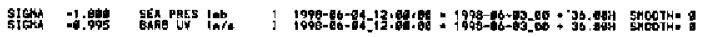
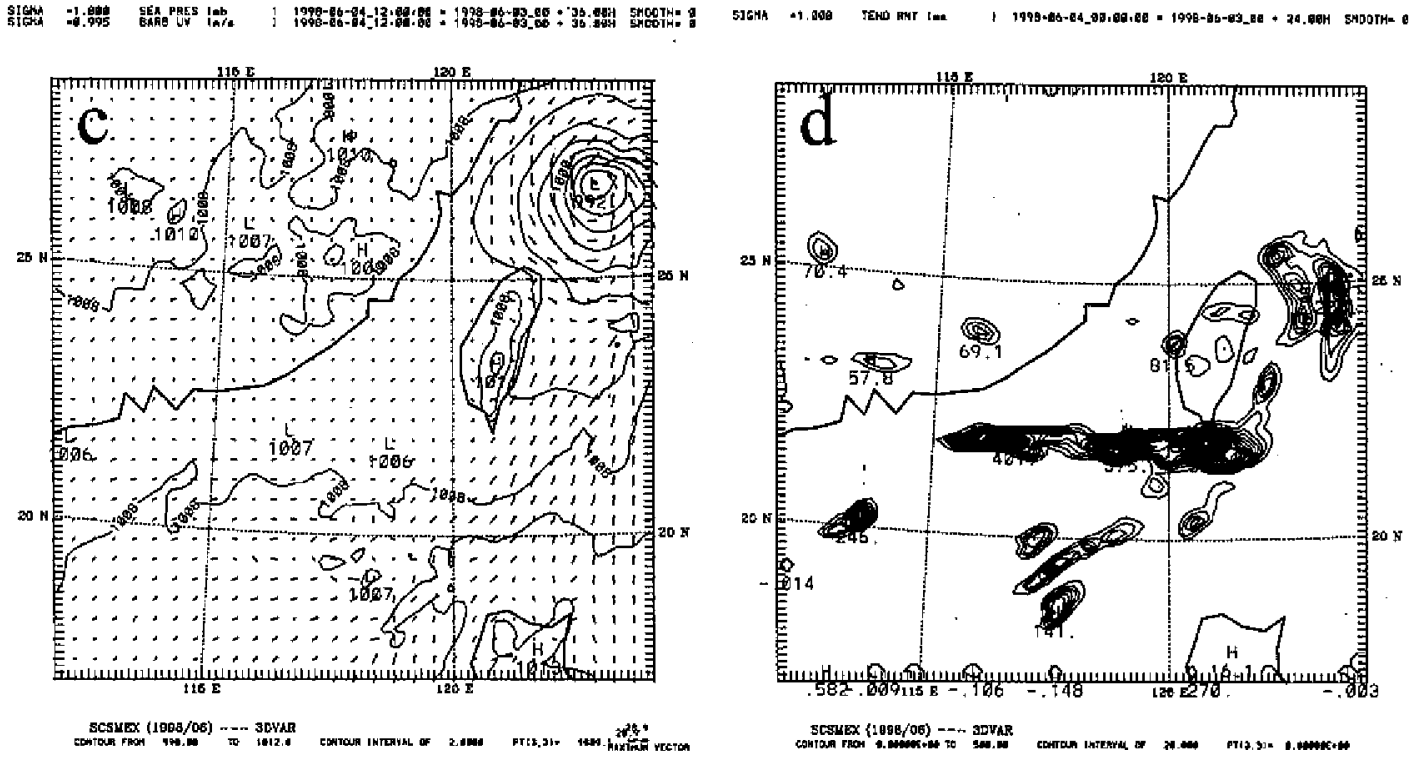

Fig. 2. As in Fig. 1 but for the run with 3DVAR. The bold line in (a) indicates the geometric positions of the surface front.

run. This lined cloud cluster has persisted for more than 6 hours as inferred from later IR images (not shown). In addition, the geometric locations of intense rainfall for the run without 3DVAR appear to be closer to the northeastern coast of Taiwan, which is not consistent with the observed offshore development of cloud convection. Although there are some discrepan- 

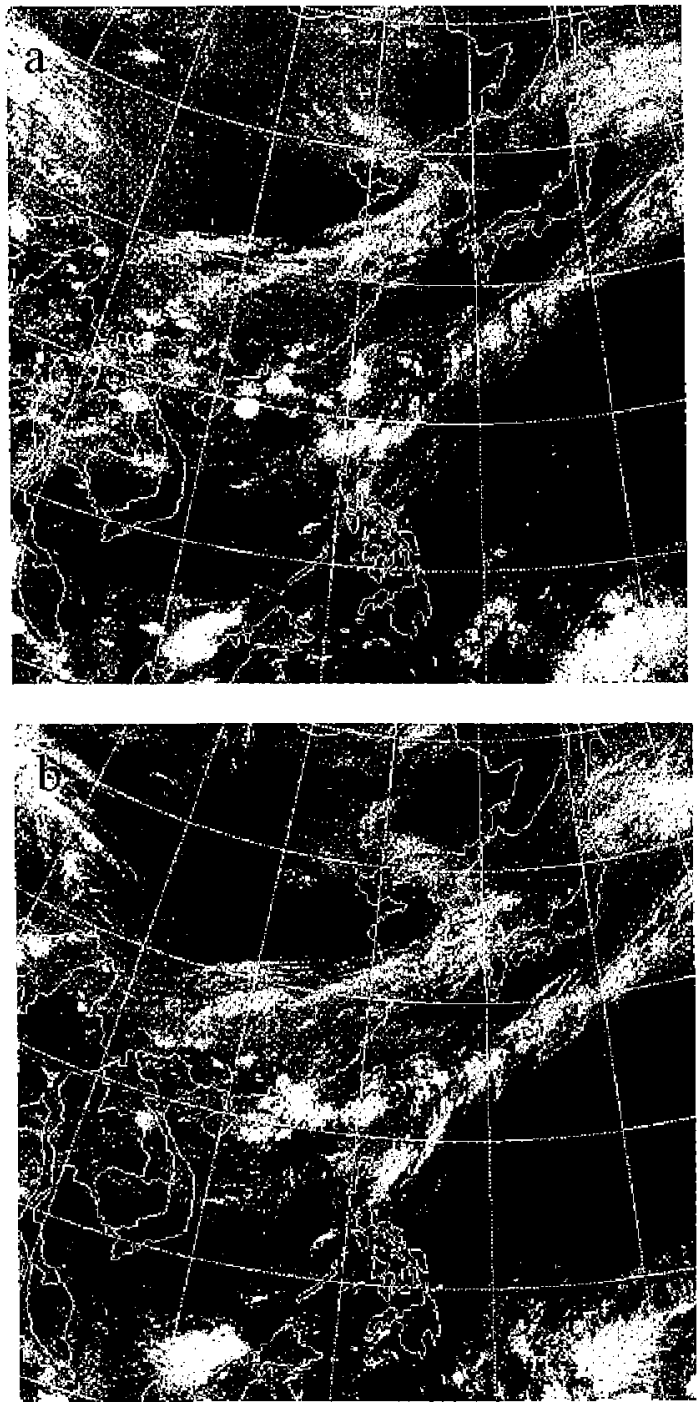

Fig. 3. Infrared satellite imagery at (a) 2133 UTC 3 June 1998 and (b) 0033 UTC 4 June 1998.

cies between the observed and the simulated, the performance for the 3DVAR run is generally more acceptable, though not significantly better, in terms of phase and location of cloud convection.

The above simulated rainfall pattems and observed cloud imagery can also be well indicated by model hydrometers. The distributions of simulated cloud water contents at $500 \mathrm{mb}$ at 1800 UTC and 2100 UTC 3 June 1998 are shown in Fig. 4 for both runs, which were found to be similar to the distributions of rain water contents (figure not shown). It can be seen clearly in this figure that cloud convection off the southern tip of Taiwan is aligned mainly westward for the 3DVAR run, consistent with the rainfall patterns as shown in Fig. 2d. There is also consistent moderate cloud development in central Taiwan for the 3DVAR run (Fig. 4c), which, however, is absent in the no-3DVAR run (Fig. 4a). 

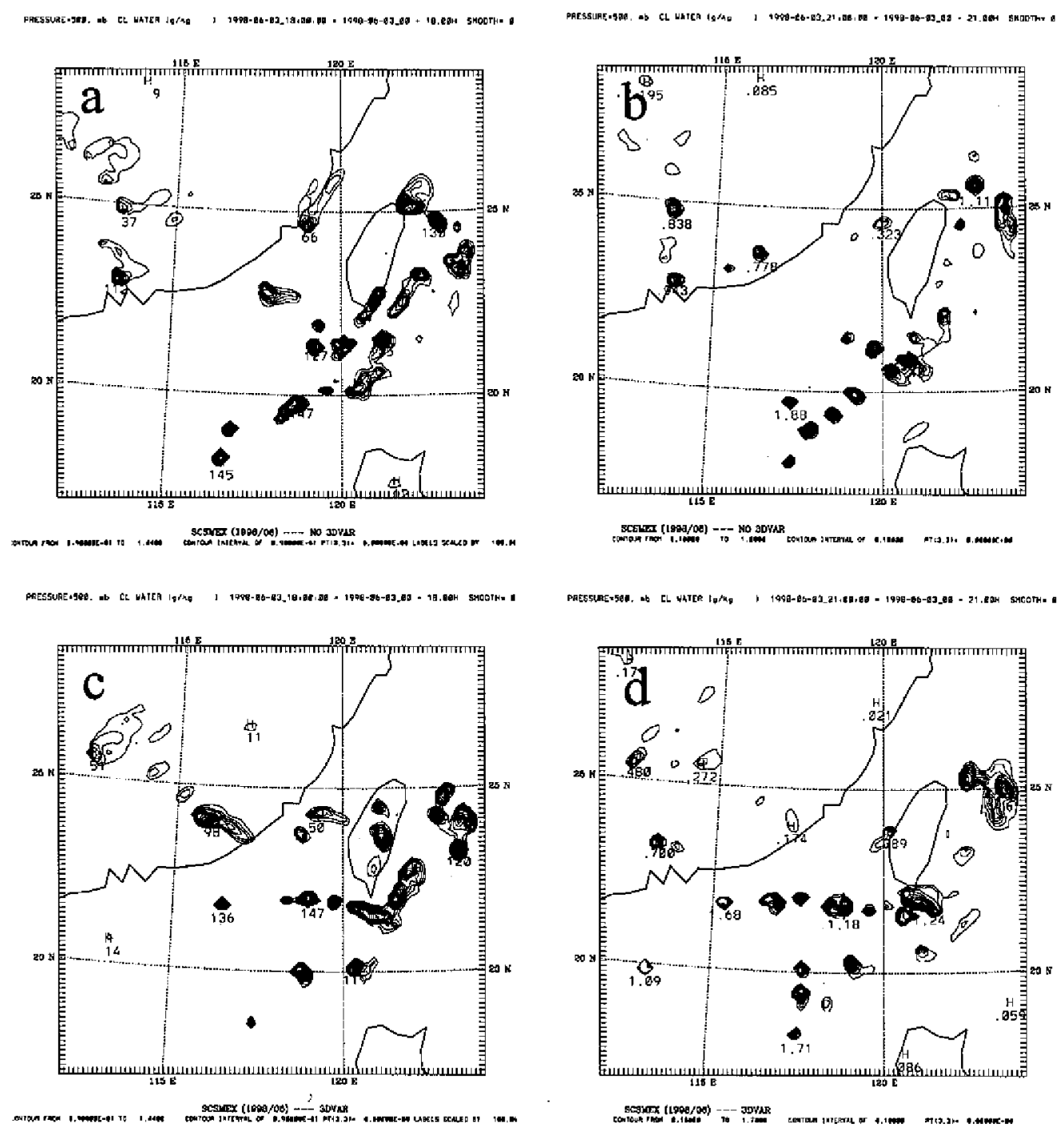

Fig. 4. (a) Cloud water contents $\left(\mathrm{g} \mathrm{kg}^{-1}\right)$ at $500 \mathrm{mb}$ at $1800 \mathrm{UTC} 3 \mathrm{June} 1998$ for the run without 3DVAR, (b) as in (a) but at $2100 \mathrm{UTC}$, (c) as in (a) but for the run with 3 DVAR, and (d) as in (c) but at 2100 UTC.

The presented results seem to be somewhat sensitive to model initial conditions that can be generated by several different analysis schemes. To assess the role of LITTLE_R, two extra runs without LITTLE_R were conducted. Figure 5 exhibits the distributions of cloud water contents at $500 \mathrm{mb}$ at 1800 and 2100 UTC for the two runs (with and without 3DVAR). Compared with Fig. 4, the results without LITTLE_R in Fig. 5 are quite similar to those with LITTLE_R. Hence, the inclusion of LITTLE_R in the model initialization does not seem to produce appreciable differences in cloud development in the domain 2 . It should be noted 

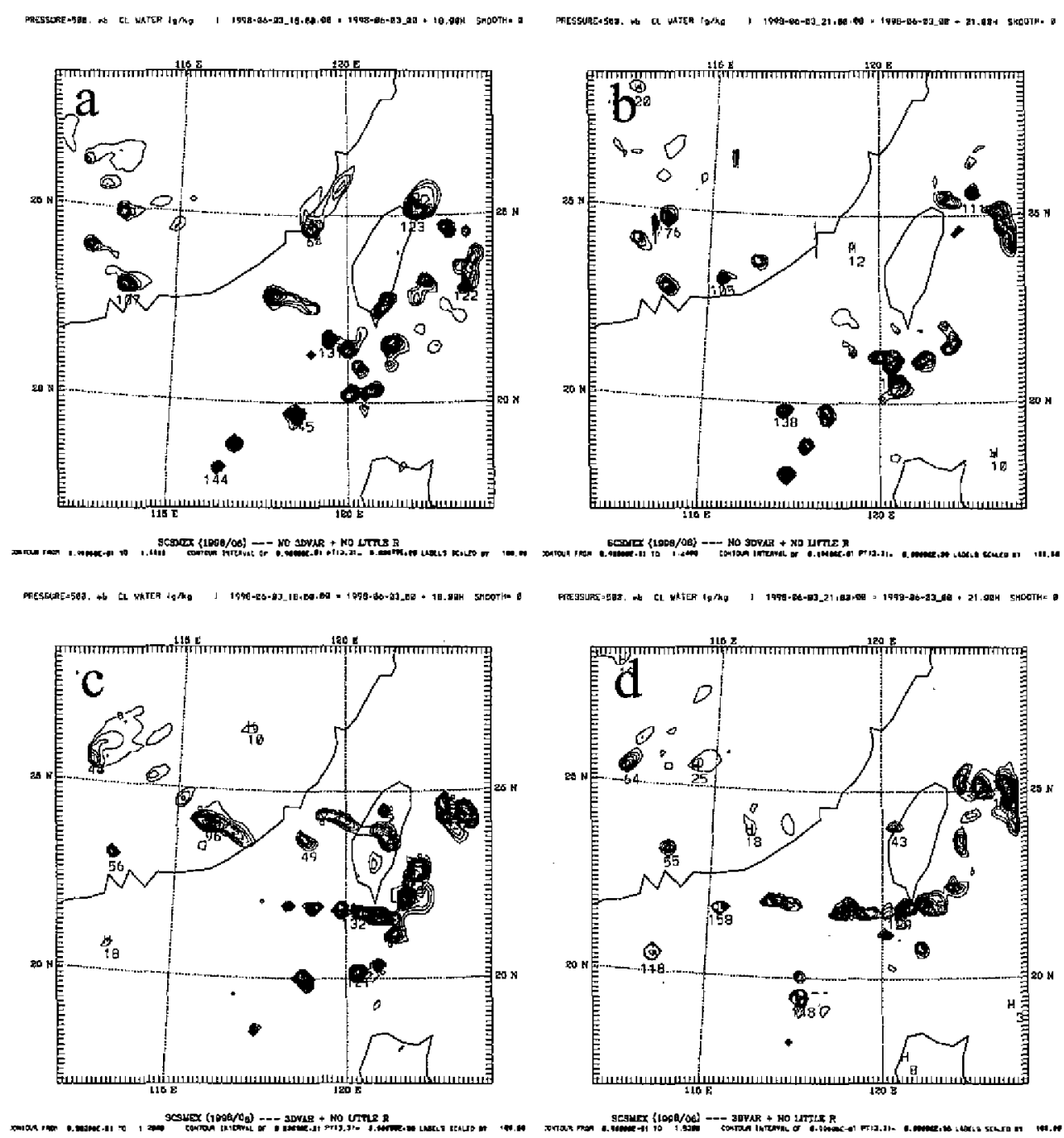

Fig. 5. (a) Cloud water contents $\left(\mathrm{g} \mathrm{kg}^{-1}\right)$ at $500 \mathrm{mb}$ at $1800 \mathrm{UTC} 03 \mathrm{June} 1998$ for the no-3DVAR run without LITTLE_R, (b) as in (a) but at 2100 UTC, (c) as in (a) but for the 3DVAR run without LITTLE_R, and (d) as in (c) but at 2100 UTC.

that the distribution of cloud water contents for the 3DVAR run without LITTLE_R (Figs. 5c, d) well resembles that for the 3DVAR run but with LITTLE_R (Figs. 4c,d). With only several case simulations in this study, broader conclusions should not be drawn for the general impact of LITTLE_R. However, the presented results tend to indicate that the 3DVAR produces more favorable model initial conditions in response to its global modulation that has not been mimicked by LITTLE_R.

It is surprising to see considerable improvement on the rainfall simulation mainly from 
the 3DVAR initialization with conventional sounding and ship observations since, as we already mentioned, LITTLE_R was also applied for objective analysis in the preprocessors of both runs. Figure 6 shows the differences between the initial perturbation pressure, horizontal wind and moisture fields at the level of $\sigma=0.995$ at 0000 UTC 3 for both runs with and without 3DVAR. There are small differences in the circulations over the oceanic regions since few sounding data are available there. It appears that corrections over the islands on the western Pacific Rim are more prominent. Over mainland China, moderate corrections are also
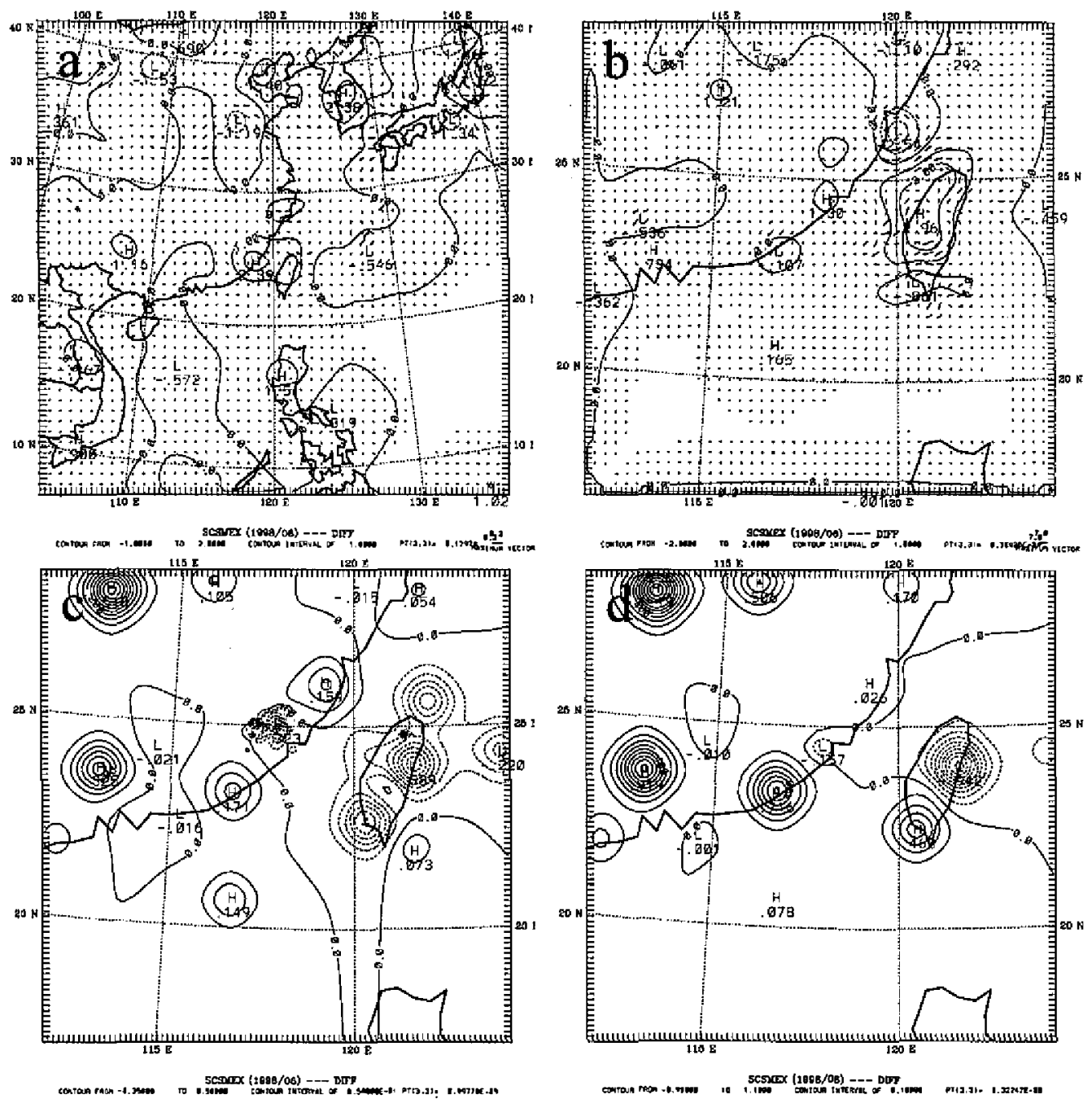

Fig. 6. The differences between the initial fields at 0000 UTC 3 June 1998 for the runs with and without 3DVAR. (a) Perturbation pressure $(\mathrm{mb})$ and horizontal wind $\left(\mathrm{m} \mathrm{s}^{-1}\right)$ at $\sigma=0.995$ in the outer domain 1, (b) as in (a) but in the domain 2, (c) for specific humidity $\left(\mathrm{g} \mathrm{kg}^{-1}\right)$ at $\sigma=0.995$ in the domain 2, and (d) as in (c) but at $\sigma=0.525$. 
produced as seen in Fig. 6a. The results in the inner domain 2 further indicate that major modifications on wind and moisture fields (Figs. 6b,c,d) are induced at the southeastern China coast and Taiwan where an anticyclonic high is embedded. A northeasterly jet is produced northwest of Taiwan in the middle of Taiwan Strait. The moisture modifications (Figs. 6c,d) have both effects of drying and moistening at different places with a maximum magnitude of about $1 \mathrm{~g} \mathrm{~kg}^{-1}$ and are more significant on several coastal spots, due primarily to the contribution of sounding observations at contiguous stations. The magnitudes of the 3DVAR moisture increments appear to increase with height. Zou and Kuo (1996) showed that the maximum moisture correction at the initial time for a mesoscale convective system could be up to $3 \mathrm{~g} \mathrm{~kg}$ 1 when the observed rainfall amounts and PW are assimilated by 4DVAR in a 3-h time window. In our case, considerable moisture increments at middle levels in southwestern Taiwan may be correlated with the later developed cloud convection extending from the southern tip of Taiwan. On the other hand, enhancement of the intensifying low in the vicinity of northeastern Taiwan may also be favored by more convergence due to the presence of the anticyclonic flow induced by the 3DVAR wind modifications. However, more sensitivity runs are needed to further identify specific contributions.

\subsection{The Typhoon Bilis Case}

The MM5 3DVAR initialization is further investigated in the typhoon case for Bilis (2000) that has also been simulated by Lin et al. (2002) using a nonhydrostatic mesoscale model (COAMPS). Based on satellite IR imagery, Bilis was categorized by Central Weather Bureau (CWB) as a supertyphoon with a maximum gust wind speed up to $65 \mathrm{~m} \mathrm{~s}^{-1}$. Bilis made a landfall at southeastern Taiwan at 2230 LST 22 August. The best track (Fig. 7a) indicates that Bilis has a roughly straight track over the high CMR with little deflection. For this typhoon with such a track, intense rainfall during the time nearing landfall (Fig. 8) is mainly produced over eastern Taiwan as a result of upslope flow of the intense vortex core.

The 3DVAR increments of the initial perturbation pressure and horizontal wind fields near the surface are shown in Fig. 9. In the outer domain 1, major pressure increments are found at northern China, Korea, Japan and southeastern Asia (Fig. 9a) and no noteworthy corrections are produced in the vicinity of Taiwan. The results in the inner domain 2 (Fig. 9b) also indicate that the corrections near Taiwan are not significant, despite that some modifications present in the vicinity of sounding stations (e.g. Kaoshiung and Taipei). The near-surface wind east of Taiwan and west of $124^{\circ} \mathrm{E}$ is somewhat westerly or northerly, which is in the opposite direction of the storm track. Considerable moisture increments up to $1.2 \mathrm{~g} \mathrm{~kg}^{-1}$ are found at these regions associated with large wind changes. However, only an increment of 0 . $3 \mathrm{~g} \mathrm{~kg}-1$ is produced near the Taipei sounding station (figure not shown). For this supertyphoon with the very moist environmental conditions, the influence of this relatively small moisture increment on the typhoon evolution may be less important.

Both no-3DVAR and 3DVAR runs for the Bilis typhoon case are initialized at 0000 UTC 21 August 2000. The initial analyses for the two runs are very similar as evident in Fig. 10, except for the surface low pressure in southern China at $30^{\circ} \mathrm{N}$ and some oceanic regions. A noteworthy feature is the contour line of 1008 -hPa pressure that crosses Taiwan only for the 

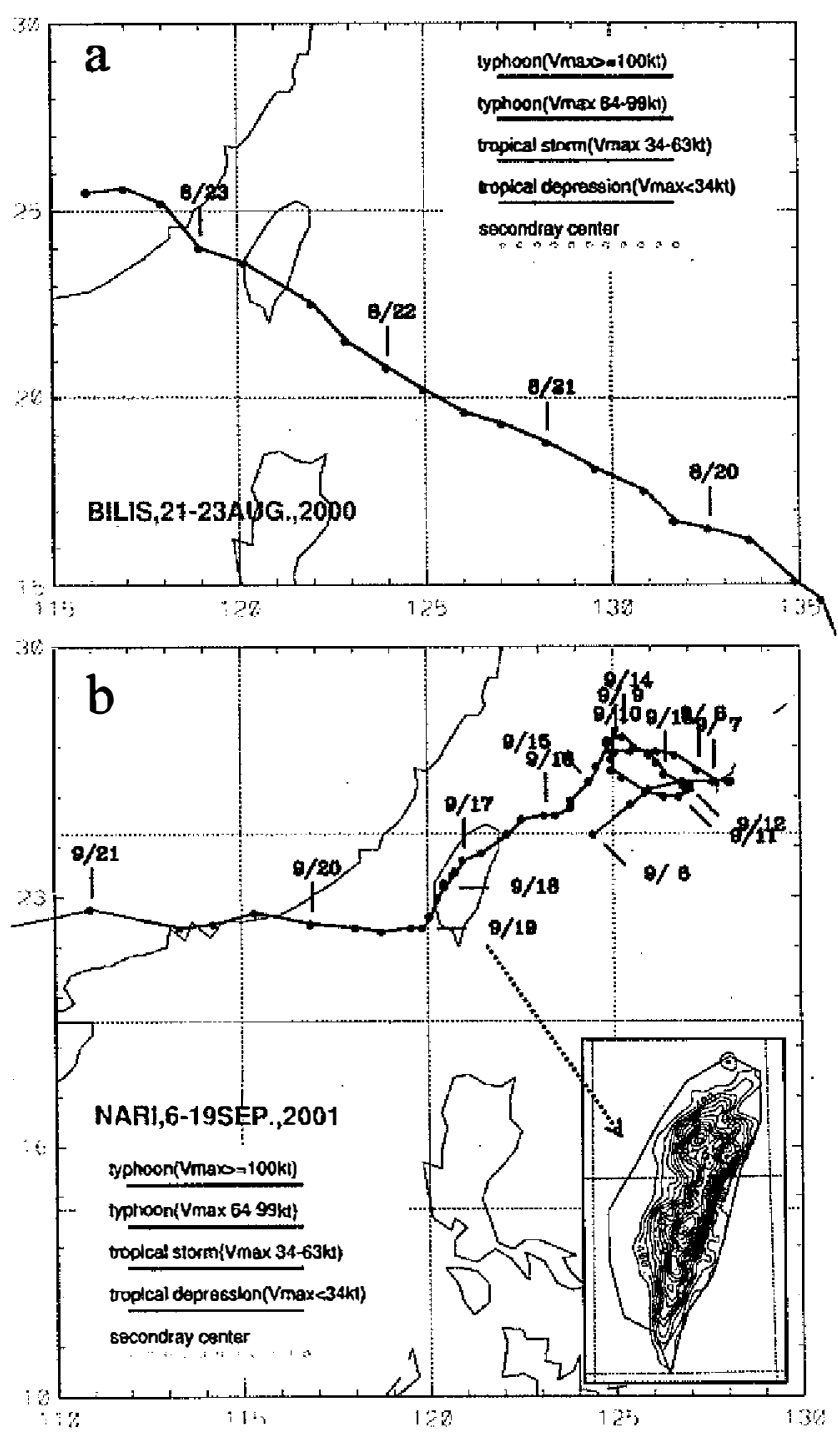

Fig. 7. The CWB best tracks for (a) Typhoon Bilis (2000) and (b) Typhoon Nari (2001). The contours of terrain elevations in Taiwan resolved in the third simulation domain are given in the lower right corner in (b) with an interval of $200 \mathrm{~m}$ and a maximum height of $2930 \mathrm{~m}$ at the peak of the Central Mountain Range (CMR).

3DVAR run. As this feature has revealed, some synoptic variations have been produced by 3DVAR modulation in the vicinity of Bilis' track. For both runs with and without 3DVAR, the initialized surface low center for Bilis at $\left(18^{\circ} \mathrm{N}, 128^{\circ} \mathrm{E}\right)$ is only $997 \mathrm{hPa}($ Fig. 10), which certainly is much weaker than the estimated actual intensity of $950 \mathrm{hPa}$.

After 36-h model integration, Bilis has deepened to $966 \mathrm{hPa}$ (without 3DVAR) and 969 $\mathrm{hPa}$ (with 3DVAR) as seen in Fig. 10. Consequently, the former gives slightly stronger nearsurface wind with a maximum speed of $51.1 \mathrm{~m} \mathrm{~s}^{-1}$. At this time, a low center of $930 \mathrm{hPa}$ was reported by CWB for Bilis about $2.5 \mathrm{~h}$ prior to landfall. Both runs appear to produce biased (lagged and northward deflected) tracks since the observed track at this time (Fig. 7a) remains southwest of the simulated. The typhoon center for the no-3DVAR run moves slightly faster 

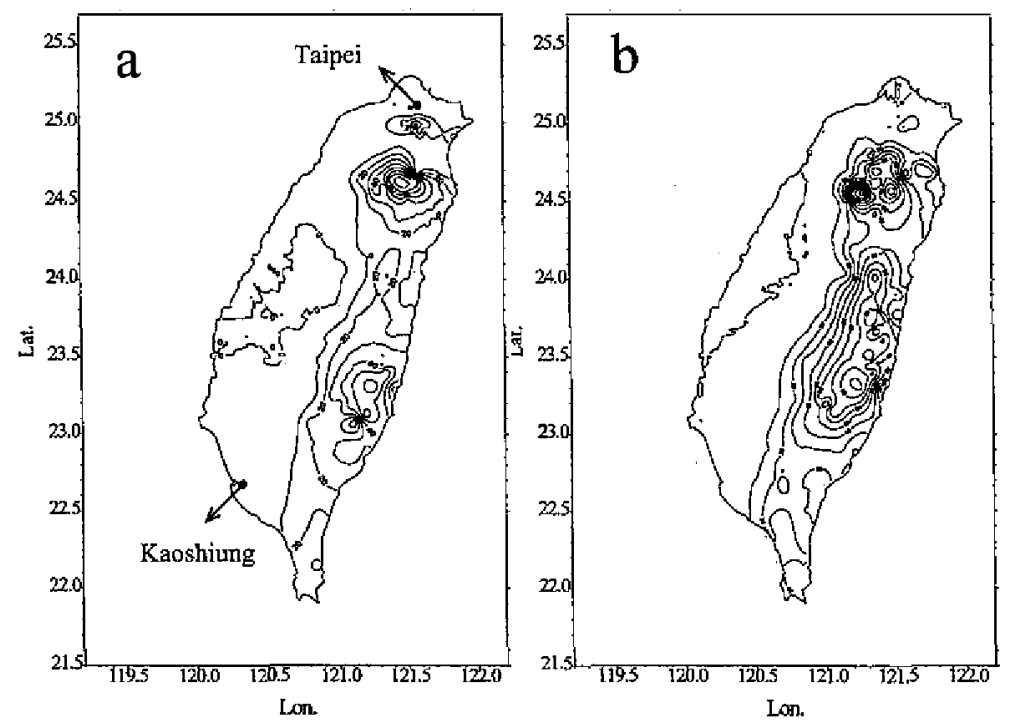

Fig. 8. The observed accumulated rainfall amounts for the Bilis typhoon case during (a) 1200-1500 UTC 22 August 2000 (88 mm) and (b) 1500-1800 22 August $2000(172 \mathrm{~mm})$. The value in the parentheses indicates maximum rainfall amount.

and the associated outer circulation is displayed more northward than that for the 3DVAR run, as seen in the 36-h forecast (Fig. 10). This may have been resulted partially from the wind modifications east of Taiwan, as shown in Fig. 9, but more elaborated analyses are needed for further understanding. With stronger wind at northern Taiwan, the 3-h accumulated rainfall amounts during 36-39 $\mathrm{h}$ are generally larger for the no-3DVAR run, as evident in Fig. 11. For example, the maximum value of the 3-h accumulated rainfall amounts just south of the northeastern CMR is $147 \mathrm{~mm}$ (Fig. 11 a) for the no-3DVAR run, as compared to $101 \mathrm{~mm}$ (Fig. 11b) for the 3DVAR run. Moreover, the geometric distributions of large rainfall amounts for the no-3DVAR run are located too southward as well as inland, as compared with observations (Fig. 8). The northward deflection in track for the no-3DVAR run has been reduced, as evident in Figs. 11c,d, when the model initial time is set forward by $24 \mathrm{~h}$ in a sensitivity run. However, the simulated central low for this sensitivity run is only $977 \mathrm{hPa}$ after 15 integration hours, and thus the rainfall intensity is slightly weaker than that for the previous two runs.

\subsection{The Typhoon Nari Case}

The simulation of Typhoon Nari in September 2001 was mainly focused on the rainfall mechanisms responsible for the enormous intensity observed in northern and southwestern Taiwan. A sensitivity test on model initialization time indicates that the simulated Nari, when starting at 0000 UTC 15, exhibits a slow southwestward movement toward Taiwan during the first two days but recurves away from Taiwan afterward. As the initial time is lagged to 0000 UTC 16 (one lay later), the simulated center for Typhoon Nari is able to make a landfall at 

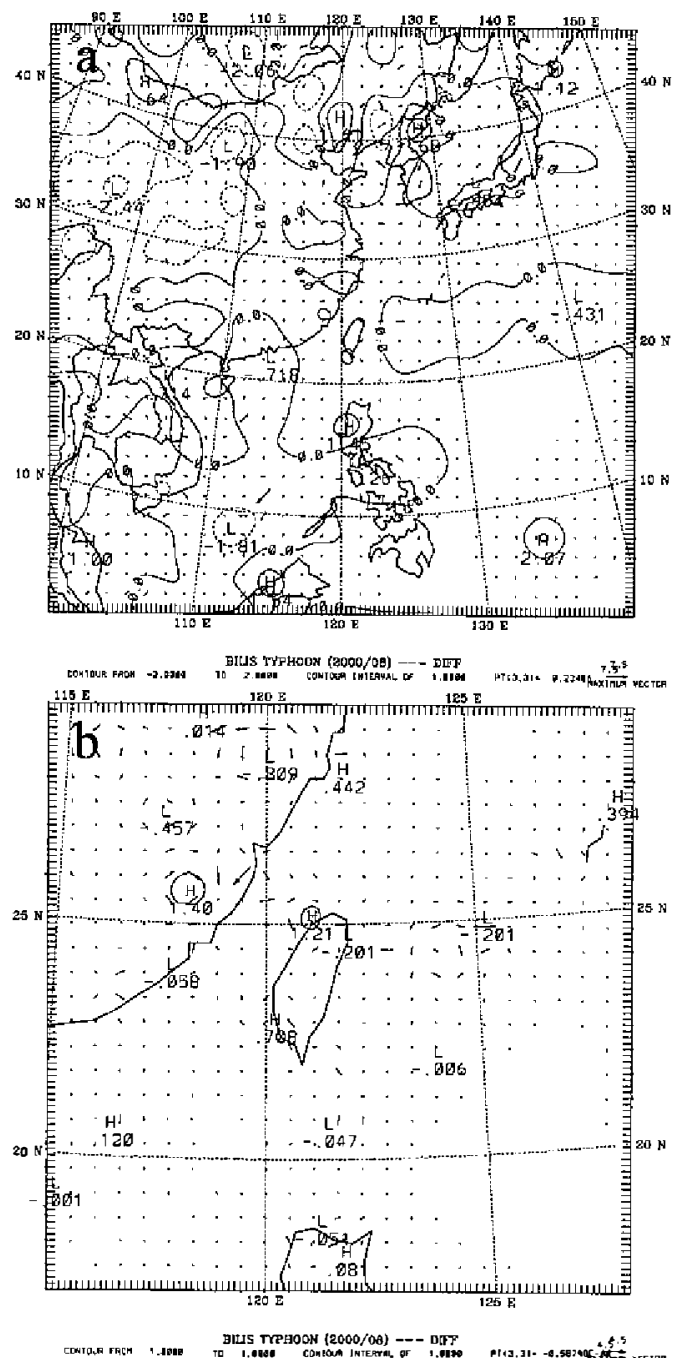

Fig. 9. The differences between the initial fields for the Bilis typhoon case at 0000 UTC 21 August 2000 for the runs with and without 3DVAR. Shown are perturbation pressure $(\mathrm{mb})$ and horizontal wind $\left(\mathrm{m} \mathrm{s}^{-1}\right)$ at $\sigma=0.995$ in (a) domain 1 and (b) domain 2.

northern Taiwan. On the other hand, it was found that NCEP global aviation (AVN) model predicted an accurate landfall on northeastern Taiwan but following a wrong track along eastern Taiwan at later times (figure not shown).

The evolving vortex circulation for Nari was well captured by the radar reflectivity echoes provided by the Wu-Fan-San radar observatory station (located near the northern tip of Taiwan). Sequential evolutions of the reflectivity echoes at every $6 \mathrm{~h}$ are shown in Fig. 12. At 0000 UTC 16, the outer spiral rainbands just impinged upon the mountain range at the northern tip. Nari then made a landfall at northeastern Taiwan at 1340 UTC 16 (Fig. 12c). The organized spiral vortex structure seemed to deform and gradually lose the characteristics of typhoon vortex after landfalling (Figs. 12e,f) but appeared to re-intensify at later times (Figs. $12 \mathrm{~g}, \mathrm{~h}$ ) as it moved slowly southward along the western slope base of the CMR (Fig. $7 \mathrm{~b}$ ). Significant rainfall was produced mainly along the upwind slope of northern Taiwan during 


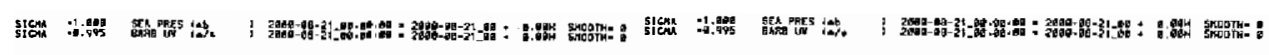
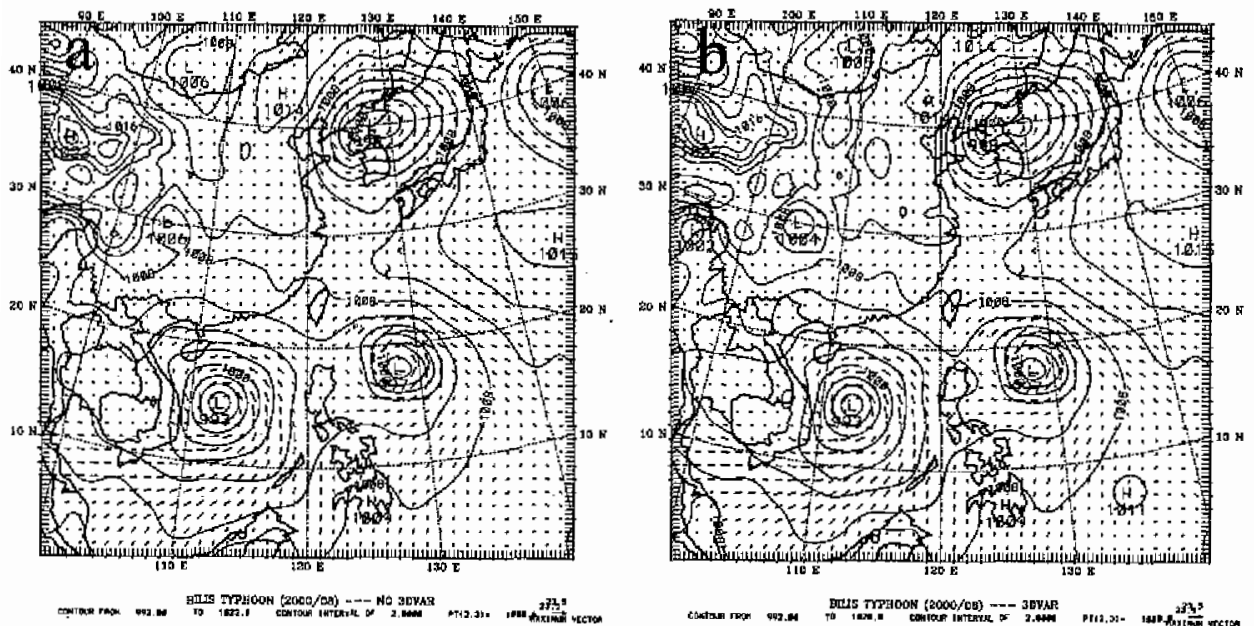

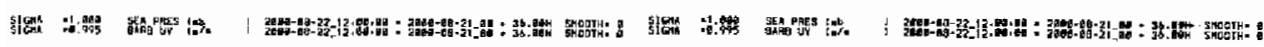
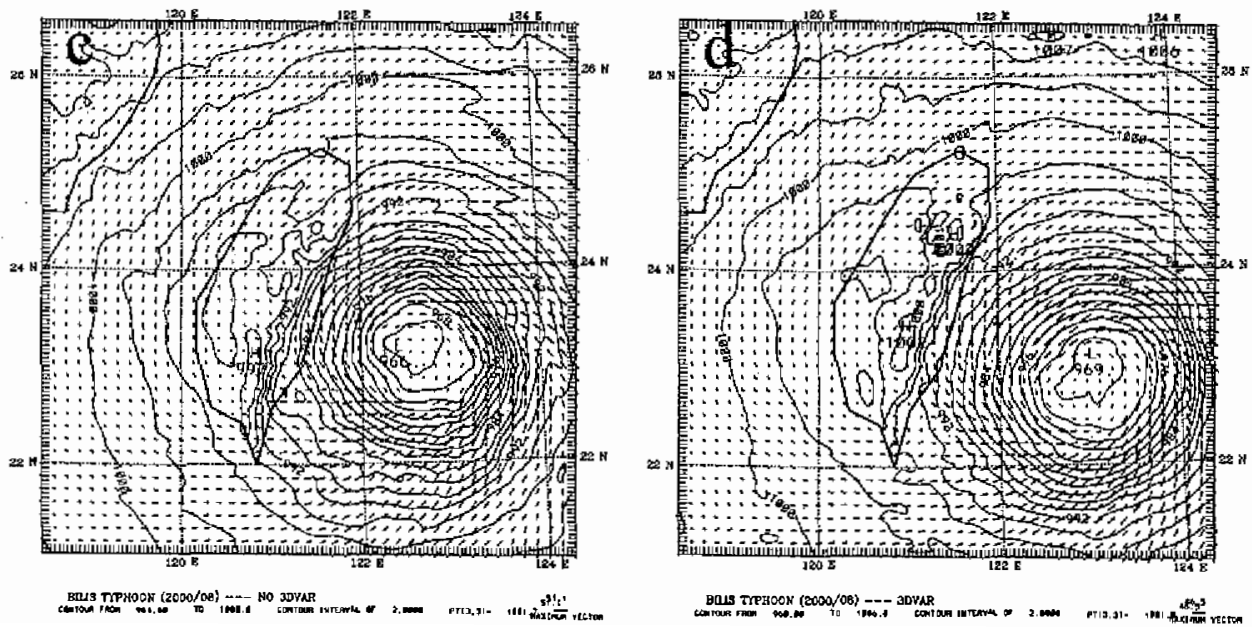

Fig. 10. The simulated sea-level pressure $(\mathrm{mb})$ and near-surface horizontal wind $\left(\mathrm{m} \mathrm{s}^{-1}\right)$ for the Bilis typhoon case (a) In domain 1 at the initial time $(0000$ UTC 21 August 2000).for the run without 3DVAR, (b) as in (a) but with 3DVAR, (c) as in (a) but for 36-h forecast in domain 3, (d) as (b) but for $36-\mathrm{h}$ forecast in domain 3.

the first stage when Nari was passing over the northern mountain range, as seen in Fig. 13a. The later re-intensification of Nari results in the tremendous rainfall in southwestern Taiwan (Fig. 13d). Consequently, the observed 24-h accumulated rainfall (not shown) on 18 September gives a maximum amount of $774 \mathrm{~mm}$ (at $23.5^{\circ} \mathrm{N}$ and $120.6^{\circ} \mathrm{E}$ ) over the southwestem slope base of the CMR.

The simulated wind and pressure fields for the run without 3DVAR for Nari are shown in 

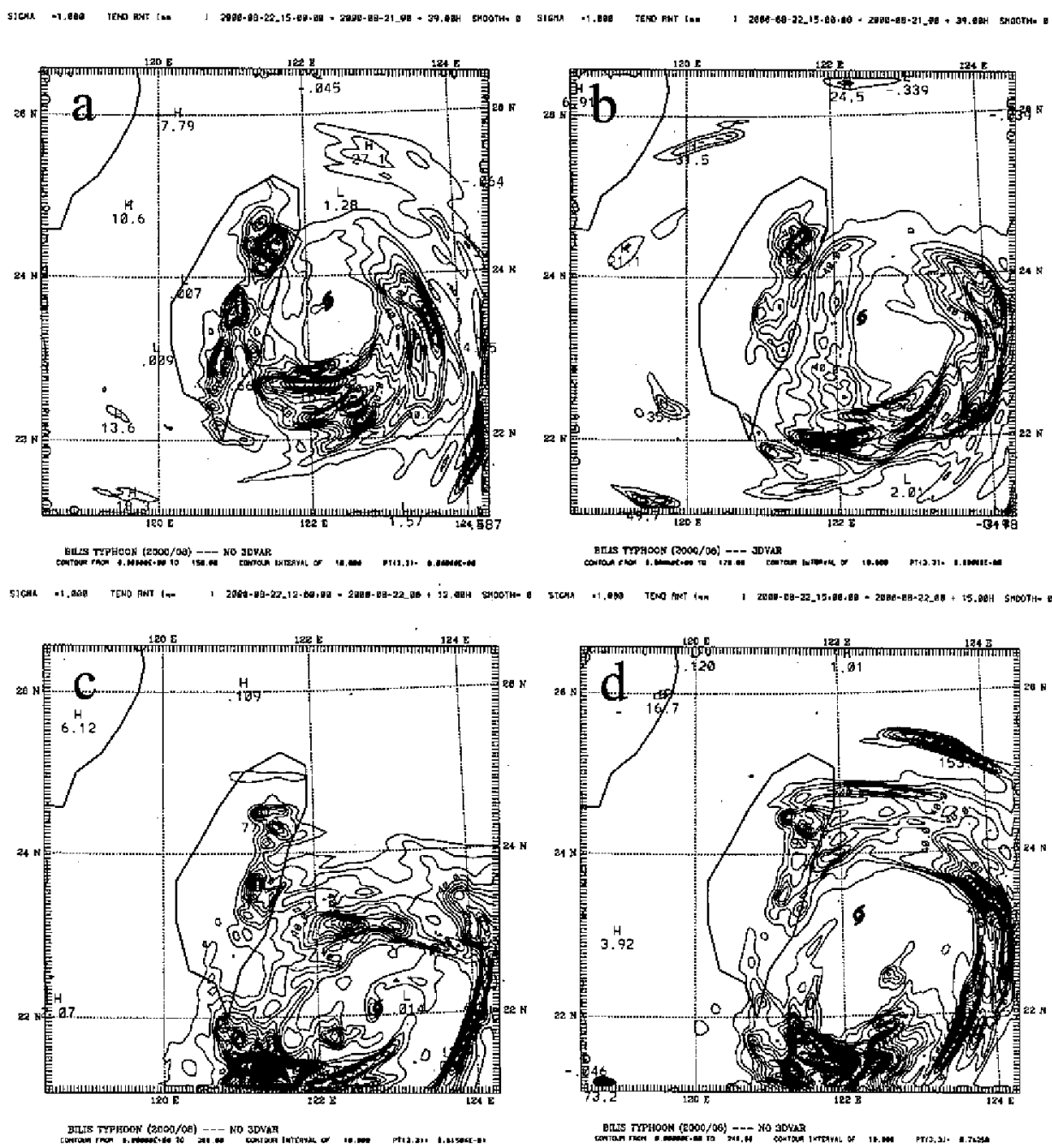

Fig. 11. The accumulated rainfall amounts for the Bilis typhoon case in August 2000 (a) during 1500-1800 UTC 22 for the run initialized at 0000 UTC 21 without 3DVAR, (b) as in (a) but with 3DVAR, (c) during 0900-1200 UTC 22 for the run initialized at 0000 UTC 22 without 3DVAR and (d) as in (c) but during 1200-1500 UTC 22. Contour interval is $10 \mathrm{~mm}$ in all panels.

Fig. 14. After 12-h integration, the surface low center strengthens to $986 \mathrm{hPa}$ at $1200 \mathrm{UTC} 16$ and is producing stronger upslope flow passing the northern edge of the CMR. In response to the upslope flow, intense rainfall has been produced during 0600-1200 UTC 16 as evident in Fig. 15a. The vortex center appears to move much slower as compared to the observations at 1200 UTC 16 (Fig. 12c). Hence, the simulated rainfall is more consistent with the observations during 2100 UTC $16 \sim 0000$ UTC 17 (Fig. 13a). Apparently, the rainfall peak in Fig. 13a 

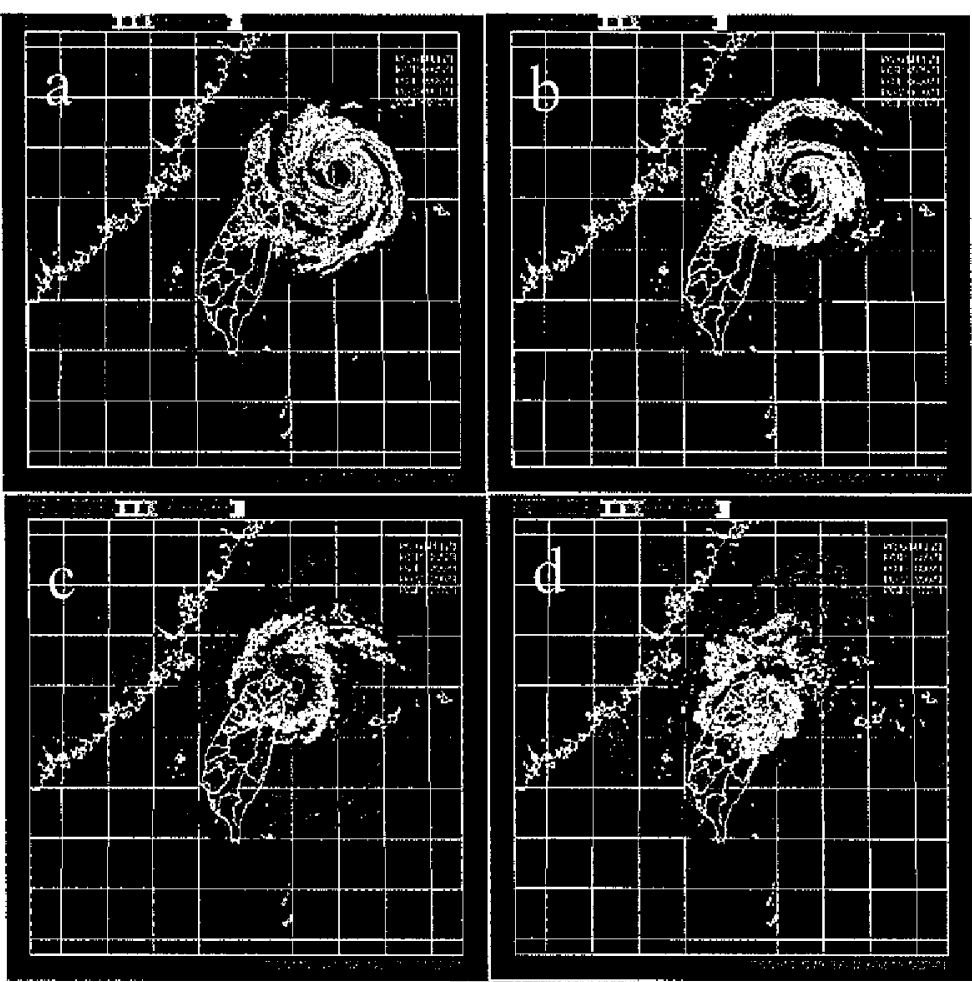

Fig. 12. Radar reflectivity echoes observed at every $6 \mathrm{~h}$ from (a) 0000 UTC 16 September 2001
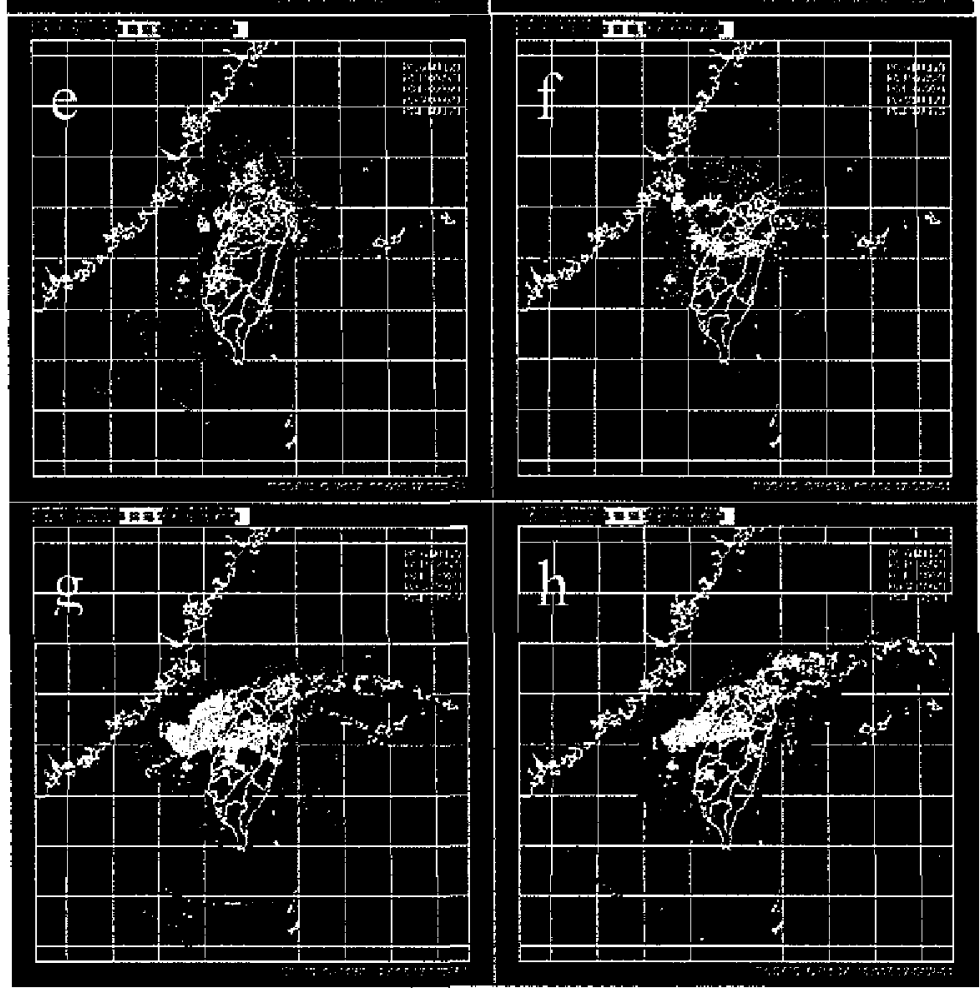
to (h) 1800 UTC 17 September 2001. (Courtesy of CWB) 


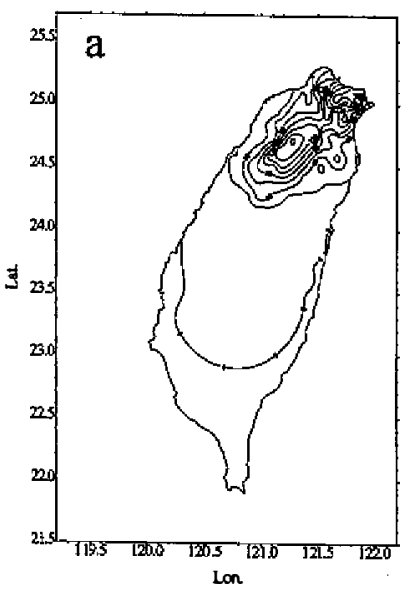

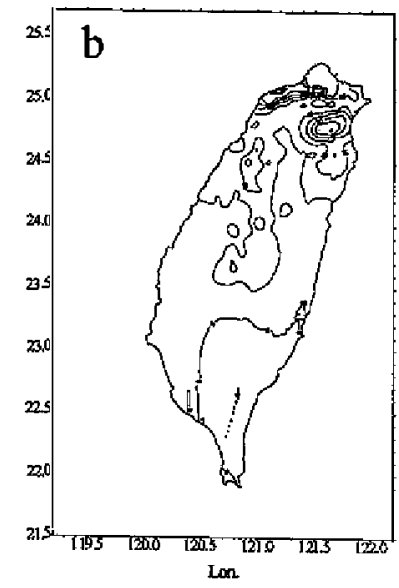

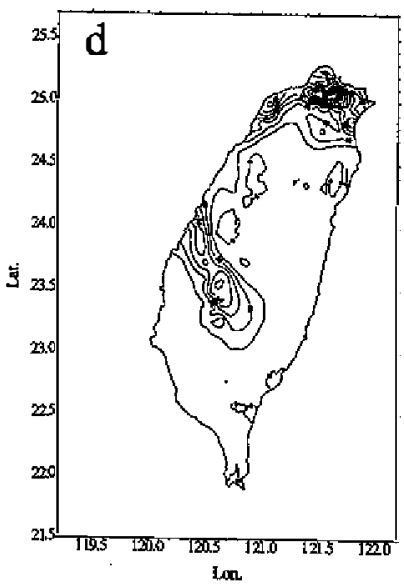

Fig. 13. The observed accumulated rainfall amounts for the Nari typhoon case in September 2001 during (a) 2100 UTC: $16 \sim 0000$ UTC $17(230$ $\mathrm{mm}),(\mathrm{b})$ 0000-0300 UTC 17 (124 mm), (c) 0300-0600 UTC $17(124 \mathrm{~mm})$ and (d) 0600 0900 UTC 17 (236 $\mathrm{mm})$.

over the mountain range at the northern tip is associated with the intense upslope flow of the inner vortex core (Fig. 14a) and is believed to be also related to the intensifying cloud convection as stagnated by topographic blocking.

As the vortex core moves to the northwestern coast, the upslope flow in the vicinity of the mountain range at the northern tip disappears and migrates southward at 1800 UTC 16 (Fig. 14b). The associated major rainfall also moves southward and extends roughly along the northwestern slope of the CMR (Fig. 15b). In fact, no intense rainfall is produced outside the intense vortex circulation and over the lee side of the CMR, indicating that the mechanism for the intense rainfall may be due to enhancement of the cyclonically rotating rainbands as they confront with the steep topography (Figs. $14 \mathrm{~b}$ and $15 \mathrm{~b}$ ). At $24 \mathrm{~h}$, the simulated vortex center has moved southwestward and the upslope flow is less prominent over the CMR (Fig. 14c); consequently, the rainfall peak does not occur near the steepest slope of the CMR (Fig. 15c). It appears that the inland flow of the vortex core near the northwestern coastal region is suddenly compelled into the frontal region with topographically-blocked flow. This convergent process produces upward motions with abundant moisture fluxes for rainfall enhancement.

At $36 \mathrm{~h}$, the upslope flow has subsided as the vortex center moves somewhat southwest- 


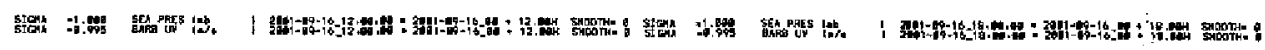
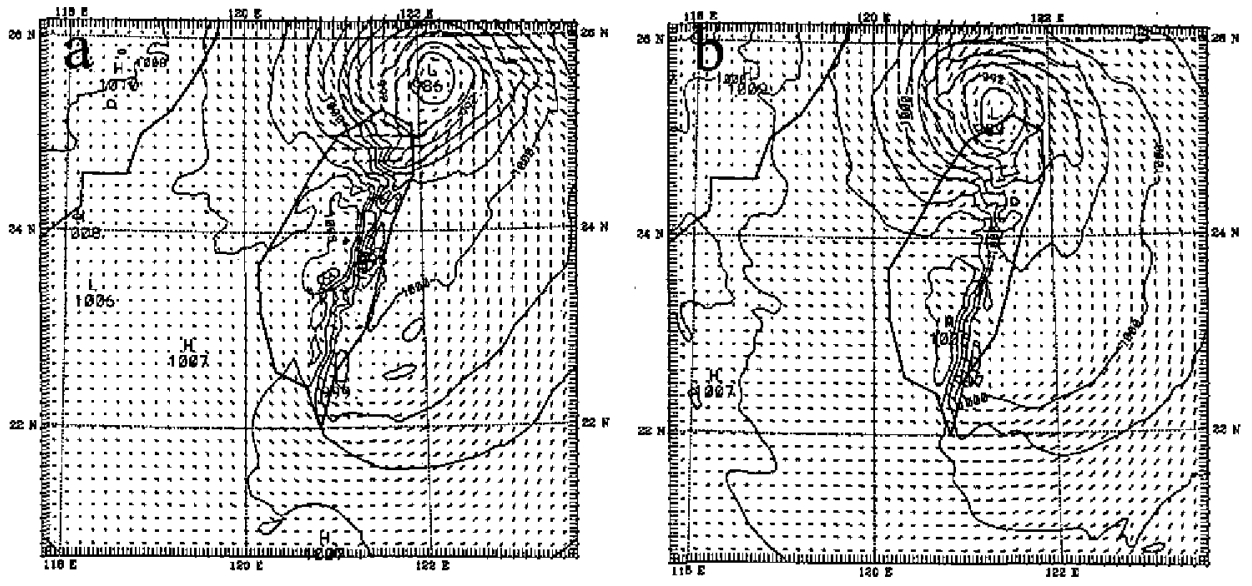

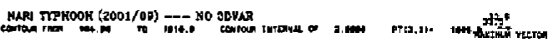

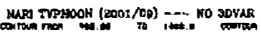

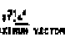

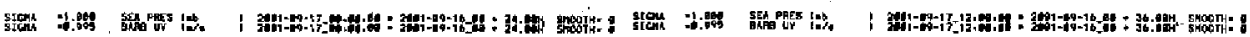
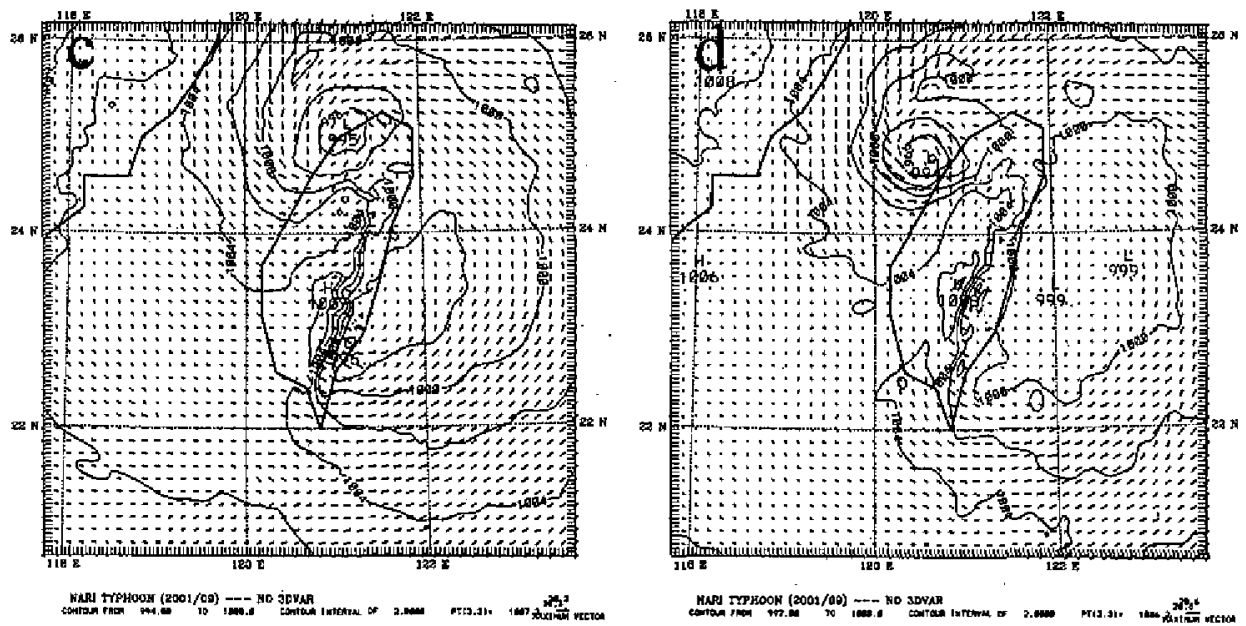

Fig. 14. The simulated sea-level pressure $(\mathrm{mb})$ and near-surface horizontal wind $\left(\mathrm{m} \mathrm{s}^{-1}\right)$ in the third domain 3 at different times for the run without 3DVAR for the Nari typhoon case in September 2001 (initialized at 0000 UTC 16). (a) 1200 UTC 16, (b) 1800 UTC 16, (c) 0000 UTC 17 and (d) 1200 UTC 17.

ward (Fig. 14d). As a result, the rainfall intensity during $30-36 \mathrm{~h}$ is much weaker (figure not shown). The simulated vortex center keeps a slow southwestward movement roughly along the coast by $48 \mathrm{~h}$. The vortex circulation at $48 \mathrm{~h}$ is associated with more inland flow (figure not shown), and hence results in intense rainfall in the southwestern region of the island (Fig. $15 \mathrm{~d}$ ). By $72 \mathrm{~h}$, the vortex center moves further southward to the southwestern coast and the associated rainfall also extends more southward (not shown). The CWB best track (Fig. 7b) 

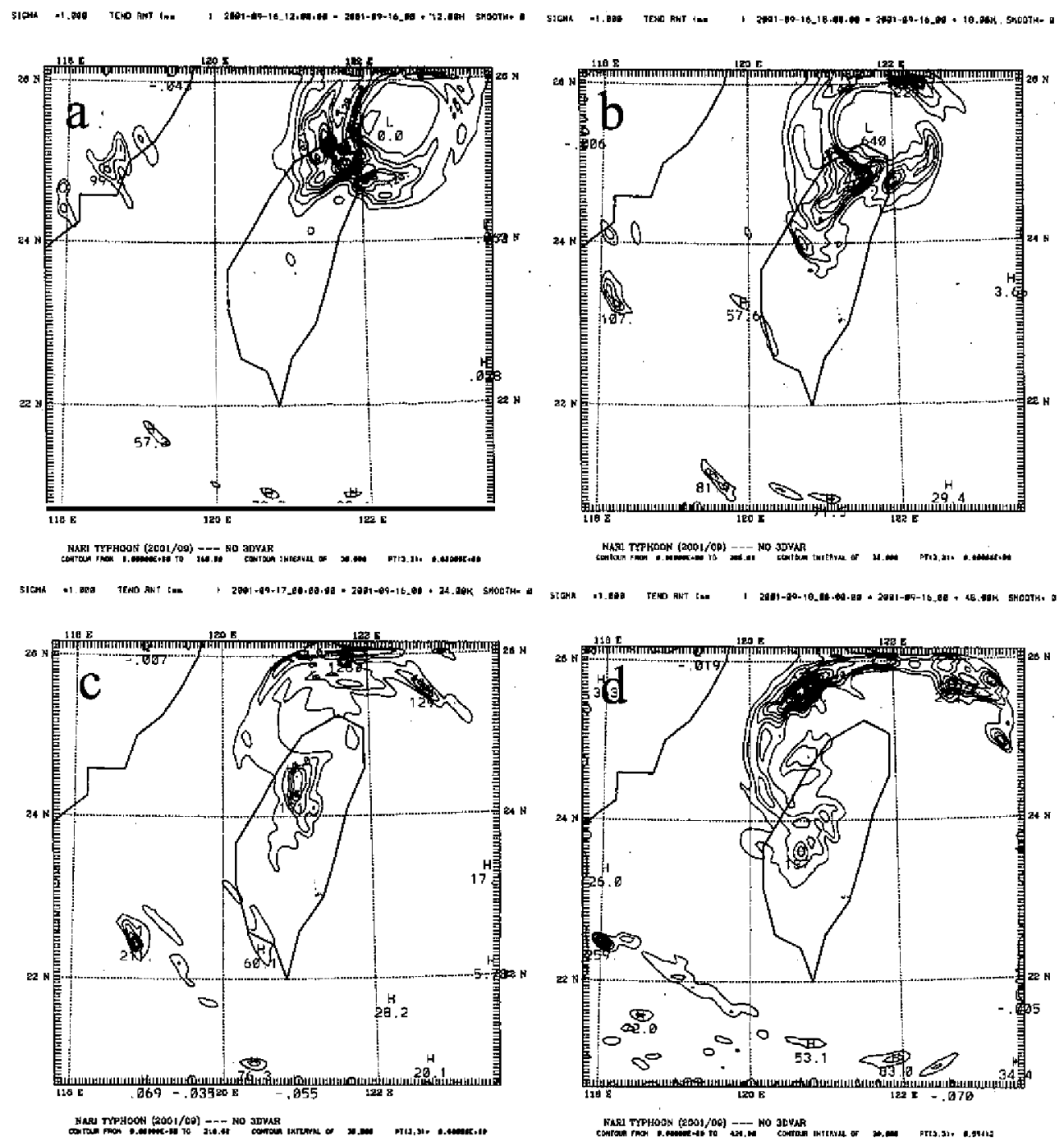

Fig. 15. The accumulated rainfall amounts in the third domain 3 for the run without 3DVAR for the Nari typhoon case in September 2001 during (a) 0600-1200 UTC 16, (b) 1200-1800 UTC 16, (c) 1800 UTC $16 \sim 0000$ UTC 17 and (d) 1800 UTC $17 \sim 0000$ UTC 18 . Contour interval is 30 $\mathrm{mm}$ in all panels.

indicates that the vortex center at 0000 UTC 19 is slightly offshore of Kaoshiung. At this time, the simulated surface low has weakened to $997 \mathrm{hPa}$ that is close to the observed intensity.

The simulated accumulated rainfall amounts corresponding to the same observation periods in Fig. 13 are shown in Fig. 16 for the run without 3DVAR. Due to the inconsistent track and movement of vortex center, as mentioned in the above, the 3-h accumulated rainfall amounts are quite different from the observations. For example, major rainfall beyond $24^{\circ} \mathrm{N}$ at earlier 
times, as found in Fig. 16a, appears more southwestward as compared to the observed (Fig. 13a). Major rainfall is produced over the western slope of the CMR at later time (Fig. 16c) but with a lead-time of at least $3 \mathrm{~h}$ and the maximum amount is also considerably smaller than the observed (Fig. 13d). Unlike the Supertyphoon Bilis case, the rainfall comparisons at exact times appear to be less satisfactory.

Although the initial vortex circulations are almost identical for both runs with and without 3DVAR, the sack simulation is improved as 3DVAR is performed in the initialization. This
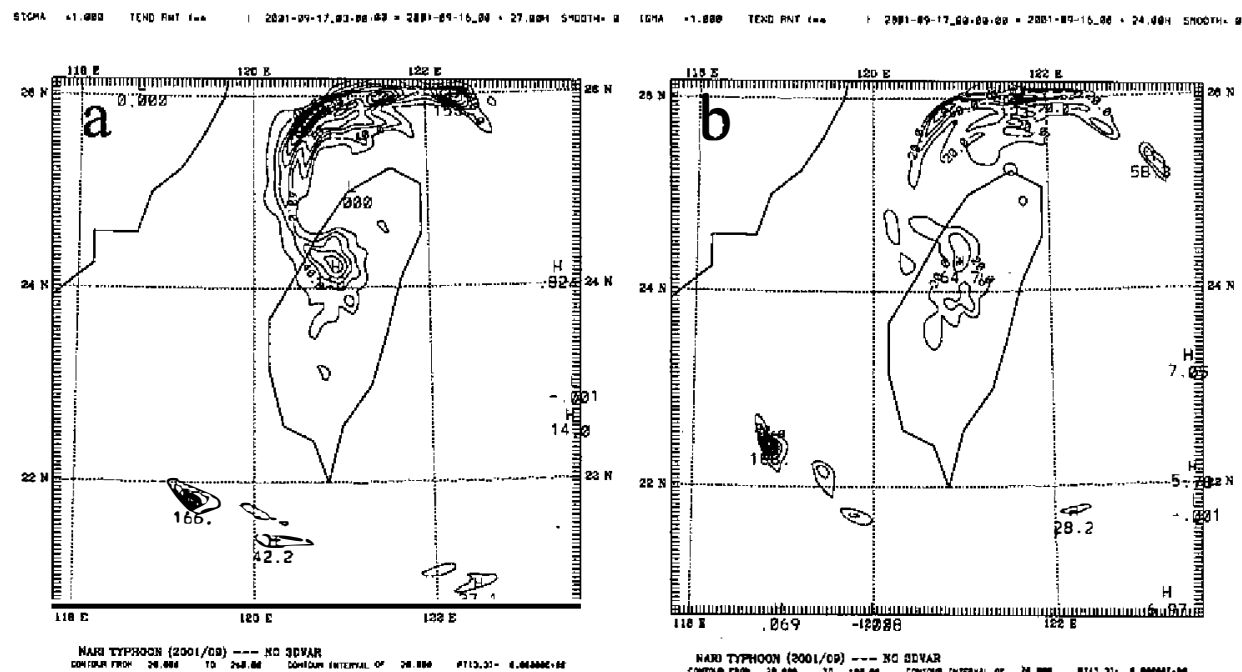

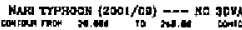

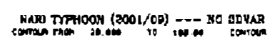

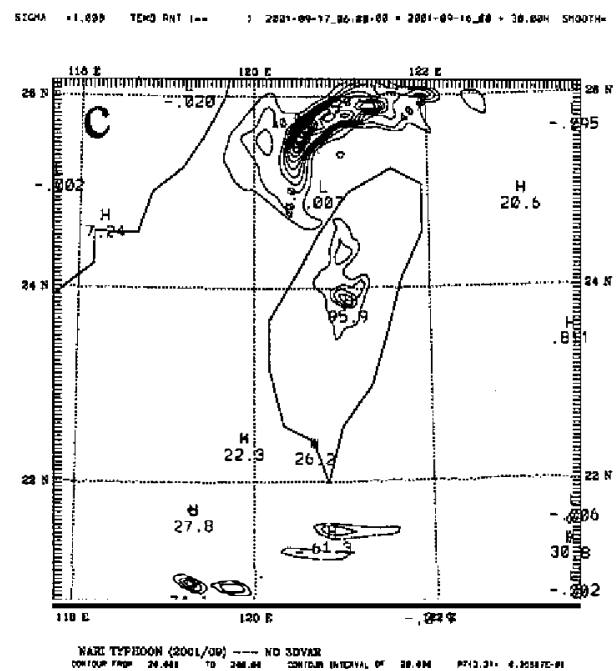

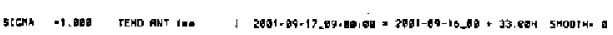

Fig. 16. The accumulated rainfall amounts in the third domain 3 for the run without 3DVAR for the Nari typhoon case in September 2001 during (a) 2100 UTC $16 \sim 0000$ UTC 17, (b) 0000-0300 UTC 17, (c) 0300-0600 UTC 17 and (d) 0600-0900 UTC 17. Contour interval is $20 \mathrm{~mm}$ in all panels. 
can be well evidenced by Fig. 17. As can be seen, the landfall position near the northeastern coast now is closer to the observed, but the vortex circulation remains situated somewhat northward. In addition, the surface center of $991 \mathrm{hPa}$ (Figs. 17a,b) is slightly weaker as compared to that without 3DVAR (Figs. 14a,b). The vortex center keeps a southwestward movement along the northwestern coast after landfalling (Figs. $17 \mathrm{c}$,d), which is not exhibited by the observed track (Fig. 7b). The vortex core is somewhat less organized as it moves along the western side of the CMR and produces more inland and upslope flow in mid-westerm Taiwan (Fig. 17d). Despite these discrepancies in the vortex's displacement and movement, the distributions of intense rainfall, as shown in Fig. 16, for the no-3DVAR run are presented for the 3DVAR run as well.
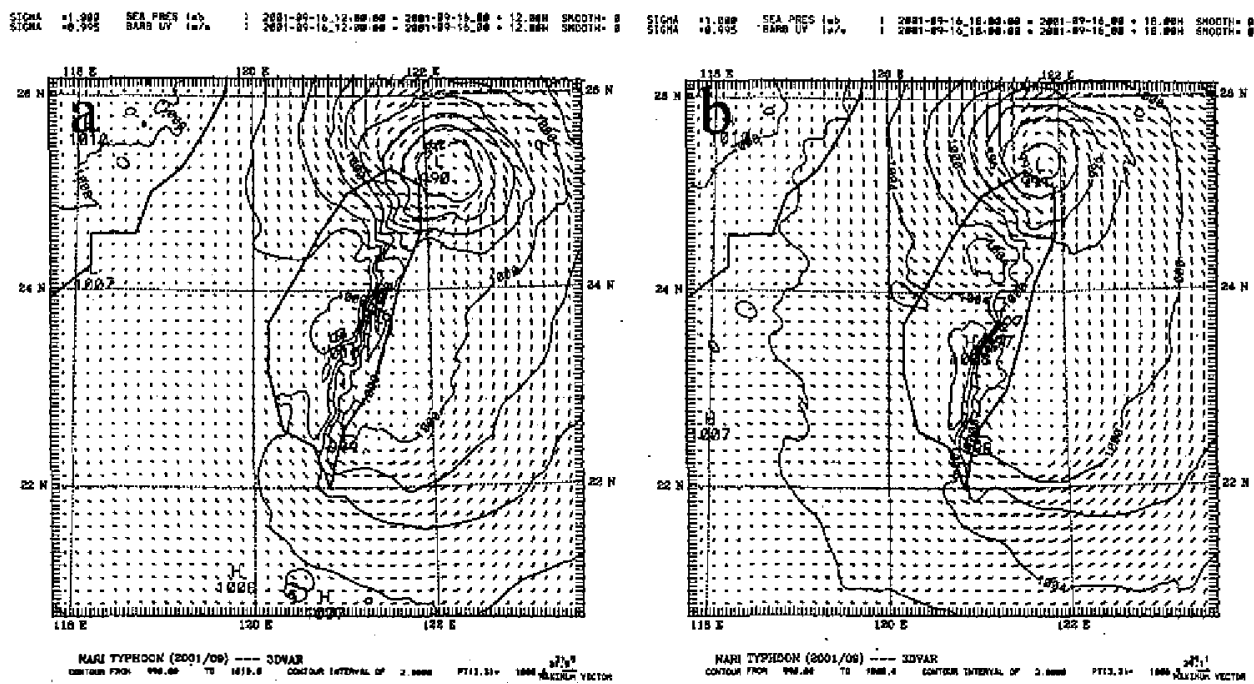

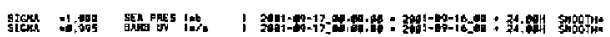
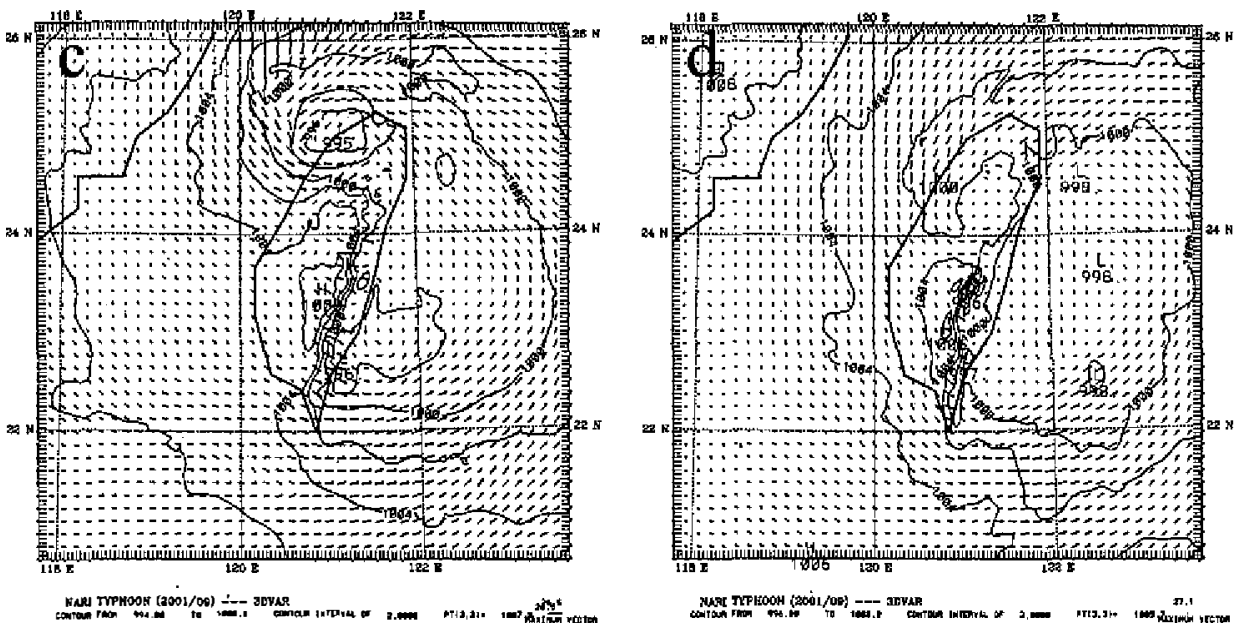

Fig. 17. As in Fig. 14 but for the run with 3DVAR. 
The rainfall comparisons at exact times corresponding to Fig. 13 are shown in Fig. 18 for the 3DVAR run. Again, due to lagging and weakening of the vortex core, the simulated major rainfall is also quite different from the observed. However, the 3DVAR run exhibits a northwestern rainfall peak at a further northward position that is closer to the observed (Fig. 13a). At a later time ( $33 \mathrm{~h}$ ), the observed rainfall peak at the northern tip (Fig. 13d) is also captured by the model, as can be seen in Fig. 18d. The rainfall activity over the southwestern slope base of the CMR is not prominent but appears to last longer for the 3DVAR run. These misrepresentations resulted from the simulated weaker vortex after landfalling. Indeed, observations as analyzed by S.-T. Wang (personal communication) tend to evidence a reorganization of the vortex core, as the vortex stagnates in the mid-western coastal region. This consolidation process of the vortex core following a slow southward movement should be the major mecha-

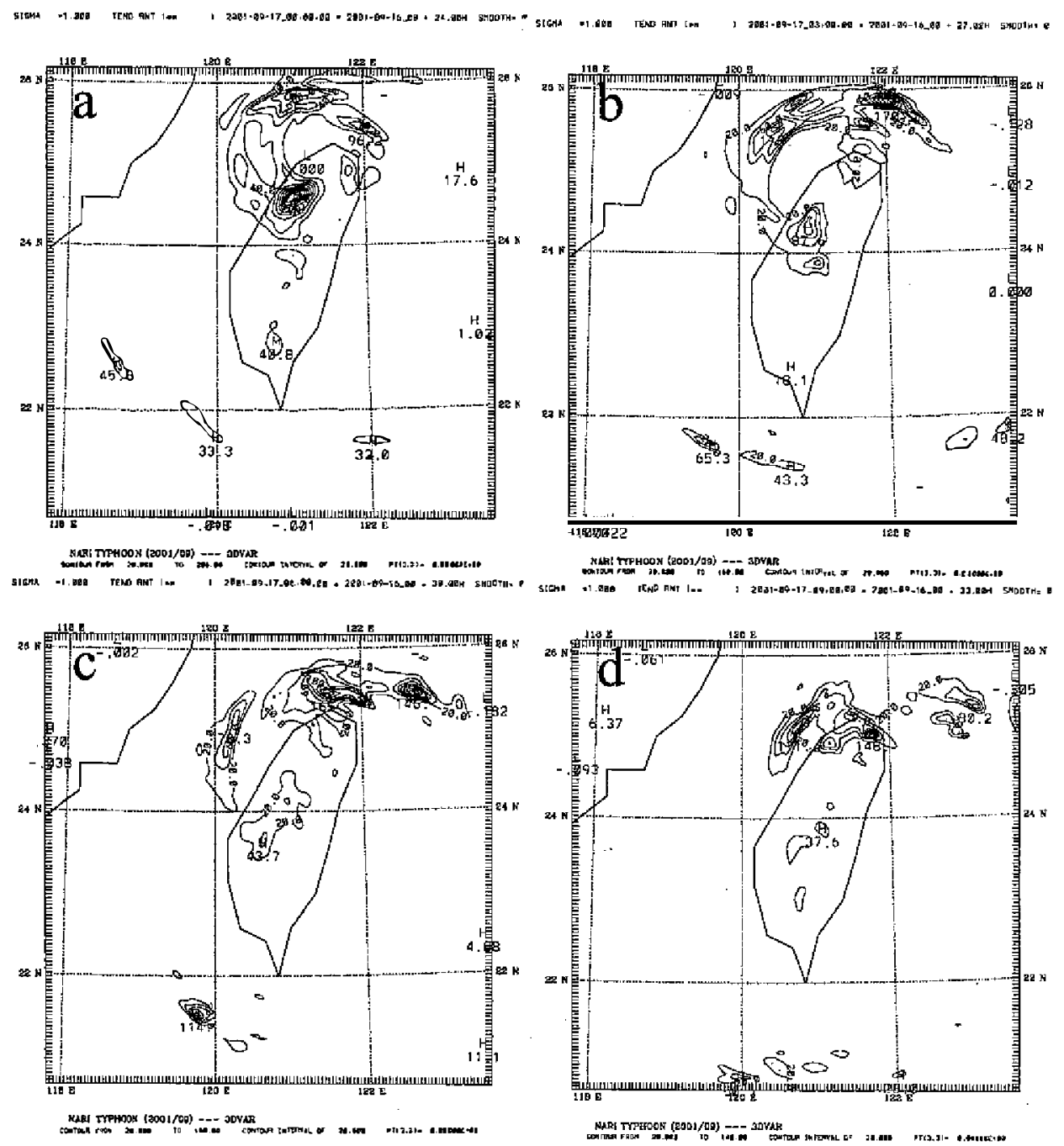

Fig. 18. As in Fig. 16 but for the run with 3DVAR. 
nism for the enormous rainfall in the southwestern slope base of the CMR, as evident in the radar observations shown in Fig. 12h.

For both runs with and without 3DVAR, the geometric distributions of their 48-h accumulated rainfall amounts are somewhat similar, as evidenced in Fig. 19. Due to weakening of the moving vortex core, they do not exhibit the observed extremely intense rainfall peaks over the southwestern slope base and the northeastern slope of the CMR (not shown). There is little rainfall in southeastern Taiwan, indicating that the inflow from the western side of the CMR

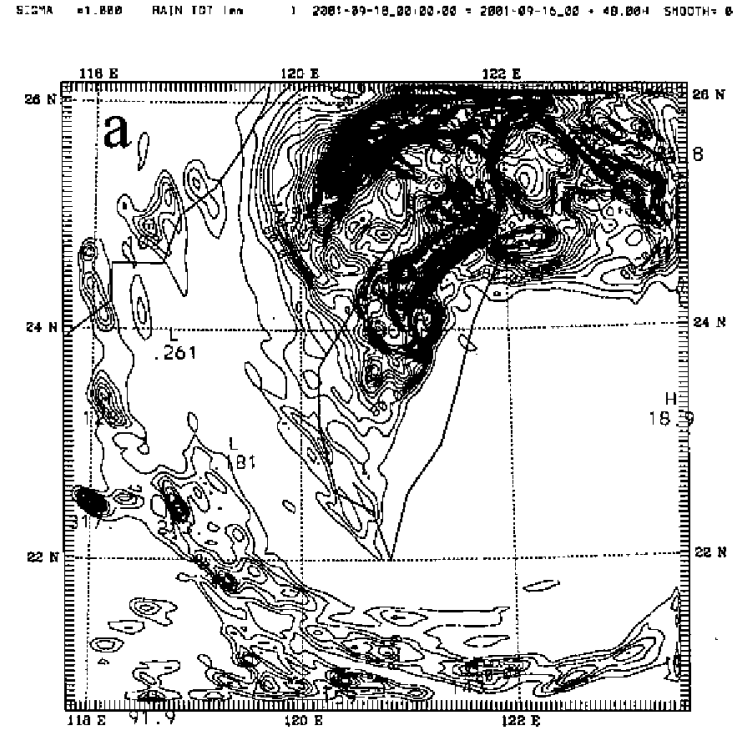

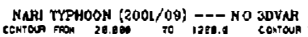

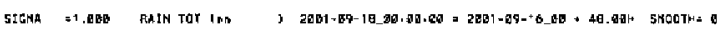

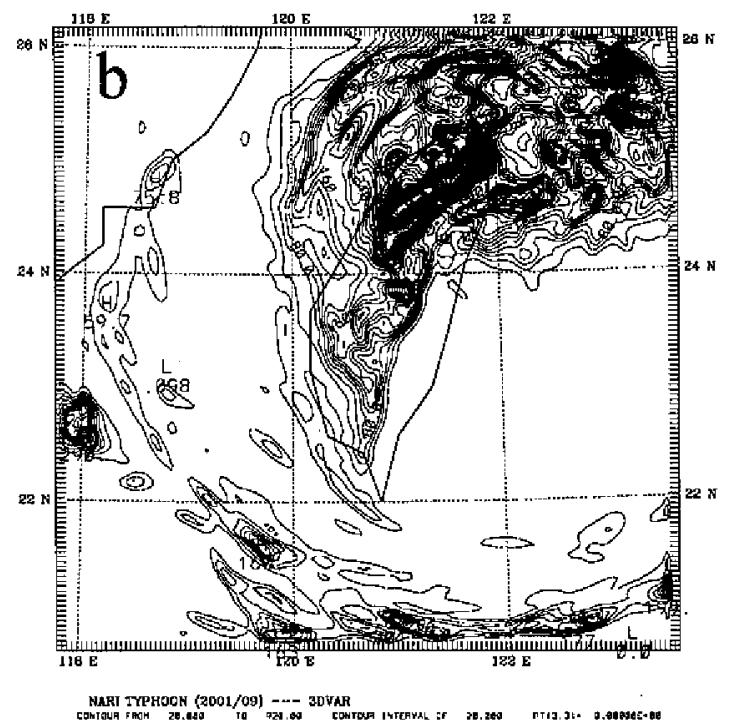

Fig. 19. The 48-h accumulated rainfall amounts in the third domain 3 for the Nari typhoon case during 0000 UTC 16 September 2001 0000 UTC 18 September 2001 for the runs (a) without 3DVAR and (b) with 3DVAR. Contour interval is $20 \mathrm{~mm}$ in all panels. 
plays an important role in the rainfall mechanisms. These rainfall patterns remain similar by $72 \mathrm{~h}$ (not shown). Features of the observed largest 72-h accumulated rainfall amount (1430 $\mathrm{mm}$ ) at the northeastern slope of the CMR and the rain-shadow area in central Taiwan are completely missed in the simulations with and without 3DVAR, indicating that complicated processes are involved in the typhoon system interacting with steep terrain.

Although the improvement on rainfall simulation of Nari is not as obvious as in the other two cases, the track simulation in fact has been improved by 3DVAR. To understand why 3DVAR has helped on track simulation, the differences between the initial perturbation pressure and horizontal wind fields at different $\sigma$-levels at 0000 UTC 16 September are shown for both runs with and without 3DVAR. In general, there are larger modifications at numerous locations over the land as seen in Fig. 20a. At the level of $\sigma=0.525$ (about $500 \mathrm{mb}$ ), the extent of modification is about half of that at the level of $\sigma=0.995$ (near the surface). The maximum increment amount in wind speed is up to $6.9 \mathrm{~m} \mathrm{~s}^{-1}$ near the surface and gradually decreases with height. It should be noted that two anticyclonic highs are produced over northern and western Taiwan coasts, respectively, in association with an offshore cyclonic low to the southeast. It might be due to the northern anticyclonic high that forces the Nari to make a more eastward landfall at earlier simulation times that is more consistent with observations. In terms of wind modification, the 3DVAR modulation has produced beneficial influences of sounding observations on the track.

\subsection{DVAR with a Bogus Vortex}

The initially resolved vortex cores for the two simulated typhoon cases are much weaker than their actual intensities estimated from available satellite imagery. Although the simulated intensity of the central pressure for Supertyphoon Bilis is able to reach $966 \mathrm{hPa}$ after 36$\mathrm{h}$ integration as shown in Fig. 10c, this intensity is still considerably weaker than the estimated true value of $930 \mathrm{mb}$. Consequently, the simulated track and evolving vortex circulation are influenced by large departures from the observations, despite that the previous rainfall comparisons are favorably good. An initially bogussed vortex that well represents the realistic intensity of Bilis may be helpful for improving the simulation. Bogussing methods that involve a complete surgical operation to remove the original vortex circulation and implant an estimated one are usually adopted in common typhoon forecast models. Before doing that, it is interesting to see whether 3DVAR is able to modulate a reasonable vortex through some prescribed observations. We tried to change the analyzed first guess and "observed" seasurface pressure at the typhoon center for Bilis to lower values (e.g. $975 \mathrm{hPa}$ ) and found that the initial 3DVAR increments in this experiment are very small at regions of typhoon circulation and thus differences in the simulation results are negligible (figure not shown). The initial imbalance, due to the insertion of a deeper typhoon center, is quickly suppressed by geostrophic adjustment to the wind field. Insertion of more data including observations near the surface (e.g. QuikSCAT retrieved wind) is worthy of investigation and could be helpful for 3DVAR to modulate a reasonable vortex at lower levels. However, according to a 4DVAR study based on observing-systems simulation experiments (OSSE), Wu et al. (2001) concluded that regains from the ingestion of pressure data only are far insufficient for the construction of 

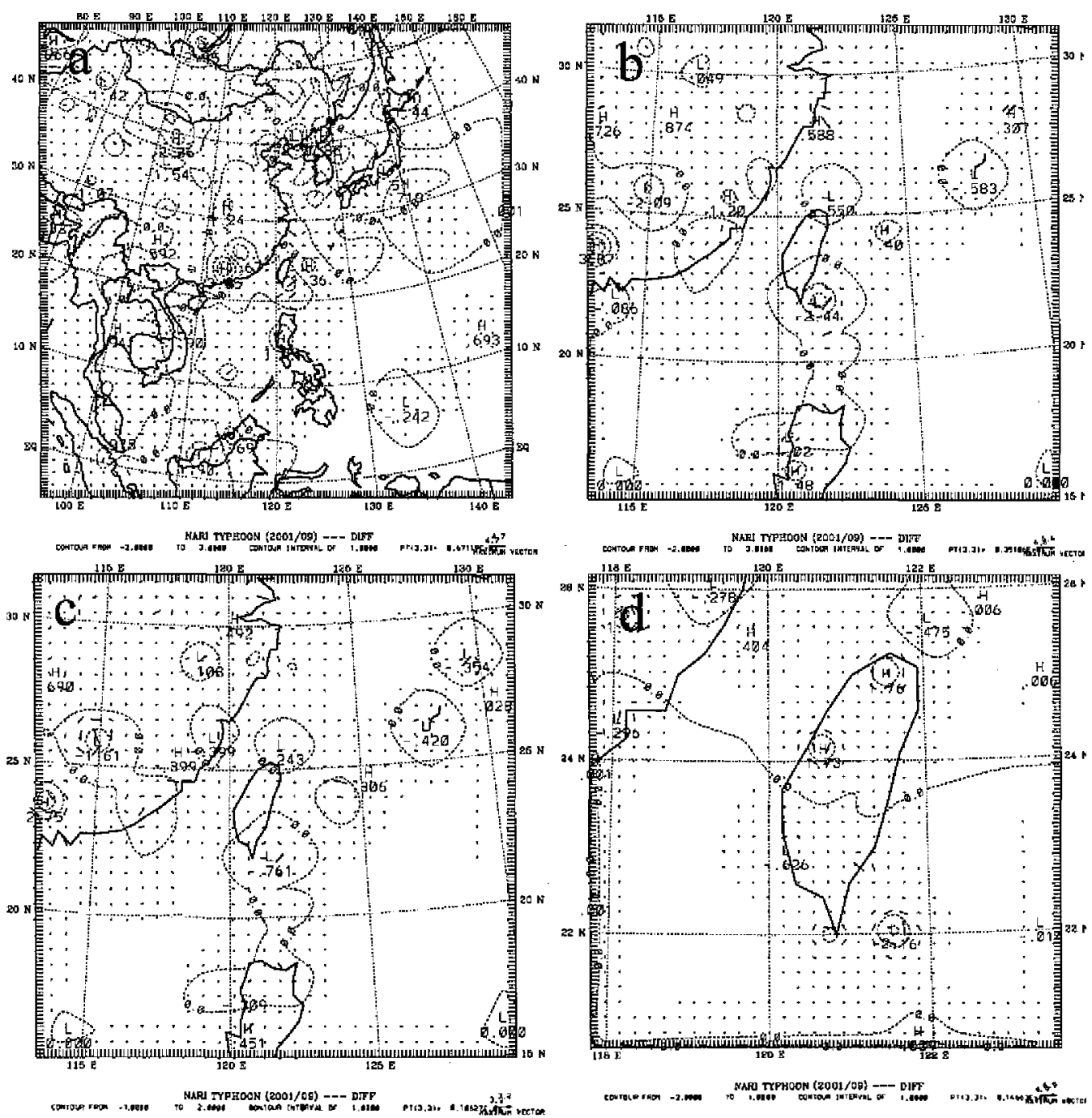

Fig. 20. The differences between the initial fields at 0000 UTC 16 for the runs with and without 3DVAR for the Nari typhoon case in September 2001. Shown are perturbation pressure $(\mathrm{mb})$ and horizontal wind $\left(\mathrm{m} \mathrm{s}^{-1}\right)$ in (a) domain 1 at $\sigma=0.995$, (b) domain 2 at $\sigma=0.995$, (c) domain 2 at $\mathrm{s}=0$. 525 and (d) domain 3 at $\sigma=0.995$.

the original typhoon vortex and the best recovery is found to rely on both inputs of wind and pressure fields in a deep layer.

As mentioned in the above, the 3DVAR modulation produces very small increments from ingestion of few presumed "observations" or first guesses as inserted. This result is primarily due to inherent weak constraints or no constraint on the flow during minimization of the cost function in 3DVAR. Hence, the information of a whole vortex in balance is required for 
3DVAR to maintain the vortex intensity in the first guesses. One of the simpler methods, as compared to the complicated one using 4DVAR (e.g. Zou and Qingnong 2000), is to adopt a bogus vortex in balanced-flow approximation and implant it into initial fields. Due to the balance checks enforced in MM5 LITTLE_R and 3DVAR, this bogus vortex should be inserted as the first guesses from global assimilated observations. We have applied the recently developed MM5 vortex-bogussing scheme to the typhoon cases. This scheme solves the nonlinear balanced equation for the bogus vortex that decays gradually in the vertical. In one experiment for Bilis, initial maximum tangential wind $\left(V_{\max }\right)$ is set to $70 \mathrm{~m} \mathrm{~s}^{-1}$ with a radius of maximum wind $\left(R_{\max }\right)$ of $50 \mathrm{~km}$. Figure 21 shows the results for the run with such a bogus vortex for Bilis initialized at 0000 UTC 21 August 2000. Compared to Fig. 10b, the insertion of the bogus vortex does not seem to create an unsmooth pressure field even associated with a much deeper center of $935 \mathrm{hPa}$. The initial differences between the bogus runs with and without 3DVAR now show more modifications over regions in and offshore of eastern China. This is believed to have resulted from the fact that bogussing the vortex may also change the first guesses outside the vortex and hence influence the 3DVAR minimization at other remote places. However, the 3DVAR increments produced in the vicinity of Typhoon Bilis are very small, indicating that the first guesses from the bogus vortex are well balanced at this oceanic region with little influence from few real observations.

The simulated intensity of the bogus Bilis, however, quickly decays to $970 \mathrm{hPa}$ in $6 \mathrm{~h}$ and then maintains a minimum of $966 \mathrm{hPa}$ prior to landfall in approximation to the intensity for the previous runs without bogussing. The simulated track of the typhoon center is also similar to those for the previous no-bogussing runs, but at a faster speed after $24 \mathrm{~h}$ as it is approaching Taiwan. At $39 \mathrm{~h}$, the typhoon center has made a landfall at the island, and hence spurious major rainfall also appears over its western region. In general, the simulated rainfall distributions for the bogussing runs with and without 3DVAR (figure not shown) are not as good as for the no-bogussing runs. It was found that the evolution of the bogus vortex is very sensitive to the chosen vortex parameters, $R_{\max }$ and $V_{\max }$. For example, in the run with a larger value of $R_{\max }($ e.g. $100 \mathrm{~km}$ ) for Bilis, the initial vortex intensity decays much more slowly to $950 \mathrm{hPa}$ within $24 \mathrm{~h}$. However, the track exhibits a large northward deflection with a landfall at the northern tip of Taiwan. We have found similar conclusions in simulations of Typhoon Nari with a stronger bogus vortex of $970 \mathrm{hPa}$. Although the simulated vortex intensity is well preserved for up to $24 \mathrm{~h}$, the vortex circulations with different values of $R_{\max }$ cannot move southward to make a landfall at Taiwan. For Nari with weaker environmental steering, the inserted bogus vortex appears to be more dominant in the vicinity of the vortex core. In this sense, the simulated track may not be in good agreement with observations since the realistic environmental situation rather than the bogus vortex is more helpful for model simulation.

It has been recognized that the movement and development of a tropical cyclone are intimately influenced by contiguous environmental conditions that can be also modified by the feedback of the developing cyclone (Anthes 1982). In our previous idealized simulations, the evolution of a westbound typhoon toward Taiwan was found to be influenced by several parameters involved in vortex initialization (Huang and Lin 1997; Lin et al. 2002). Both $R_{\text {max }}$ and $V_{\text {max }}$, in addition to ambient steering wind speed, in fact play an important role in simulations of evolving typhoons in the vicinity of the terrain. Investigation on the sensitivities of model 

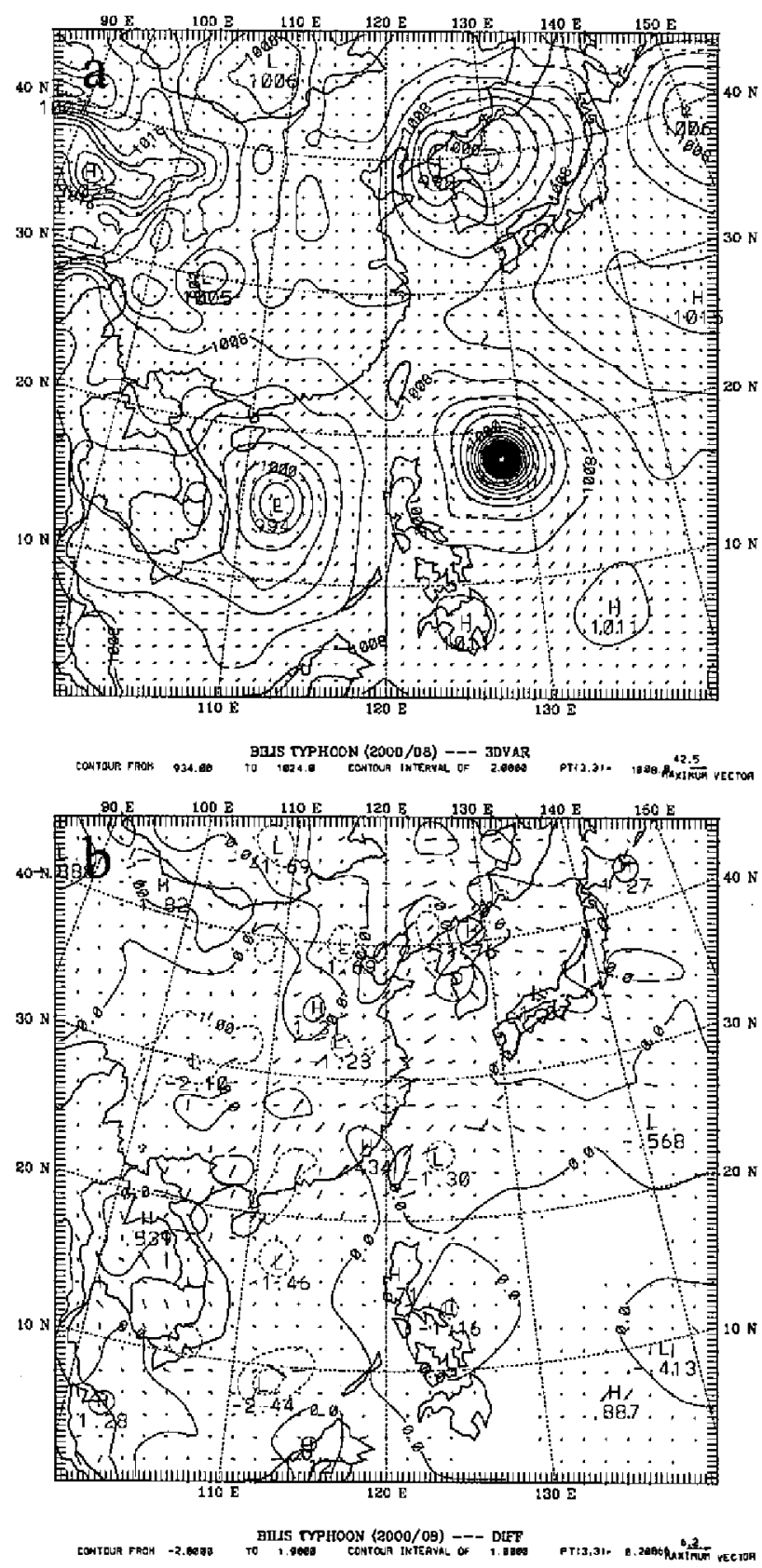

Fig. 21. (a) The total pressure field $(\mathrm{mb})$ and horizontal wind ( $\mathrm{m}$ $\mathrm{s}^{-1}$ ) in the outer domain 1 at $\sigma=0.995$ at the initial time (0000 UTC 2l August 2000) for the run with $3 \mathrm{DVAR}$ for the Bilis typhoon case, and (b) as in (a) but for the differences between the results with and without 3DVAR. The center pressure of the initial bogus vortex at (17. $84^{\circ} \mathrm{N}, 128.13^{\circ} \mathrm{E}$ ) for Bilis is $935 \mathrm{mb}$ in (a).

performance to possibly involved parameters is beyond the scope of this paper. We suggest that studying for 3DVAR modulation with an initially bogussed vortex is an important topic since it provides a basis for real-time operation. Extensive experiments of 3DVAR associated with different vortex-bogussing methods, however, are a massive task and the experimental results should be presented in other publications. 


\section{CONCLUDING REMARKS}

In this study, we have investigated the performance of MM5 3DVAR in modulation of observations as ingested into initial conditions for numerical weather prediction (NWP). As theoretically known, 3DVAR offers great potential for improving NWP due to optimal initial analyses by taking many types of observations into assimilation. We have examined the performance of MM5 3DVAR in three recent cases (one for Mei-Yu front and two for typhoons) that made great impacts on Taiwan and thus were chosen for study. As this preliminary study shows, through 3DVAR assimilation of sounding and ship observation data into the model, numerical simulations for the three cases have been improved to some extent. In the experiment of the $1998 \mathrm{Mei}-\mathrm{Yu}$ front case, a cloud cluster is produced just off the southern tip of Taiwan as 3DVAR is performed in the initialization. This cloud convection extending westward from southern Taiwan is in better agreement with IR observations as compared to that extending southwestward for the run without 3DVAR. For simulation of moderate Typhoon Nari (2001), the 3DVAR modulation also helps the typhoon center to make a correct landfall at northeastern Taiwan. For Supertyphoon Bilis (2000), the simulated intense rainfall over the eastern side of the CMR appears to be more consistent with observations for the run with 3DVAR. However, the rack simulation is only slightly improved for this supertyphoon that is far insufficiently resolved in the model initial conditions.

The limited evidences from the above three case results may not substantially illustrate the strong positive impact of MM5 3DVAR on weather prediction. Better more coherent results from all of the three case simulations, however, should provide good support for the feasibility of MM5 3DVAR in modulating influences of observations. In addition, the simulation results have demonswated the great sensitivities of model performance to small 3DVAR increments in initial conditions. This suggests that influences of observations should be modulated in some way, e.g. through the optimal minimization of 3DVAR. It was found in this study that appreciable 3DVAR increments are produced at locations with nearby observations. As evidenced by the positive impacts from 3DVAR increments, the three case simulation results suggest that sounding observations in the vicinity of Taiwan have beneficial influences on local weather prediction. A recent study of MMS 3DVAR for Hurricane Danny (1997) (Chen et al. 2002) has demonstrated that the assimilation of SSM/I data on available swaths passing the simulated cyclone is particularly helpful for intensity prediction but turns out to have much less impact on hurricane track. This tends to point out a fact that any improvement on hurricane prediction will be composed of many complicated factors. We should not be critical given the present improvements from 3DVAR in this study. Nevertheless, the favorable evidences presented in this study have stimulated us to ingest more remote sensing data (e.g. PW and QuikSCAT wind) to illustrate the great potential of 3DVAR in improving NWP.

We also investigated the performance of 3DVAR in the typhoon simulations with a bogus vortex inserted into the first guesses. Although the 3DVAR modulation well preserves the initial bogus vortex, the typhoon weakens quickly after integration. Moreover, the rack and rainfall simulations for the runs with an intense bogus vortex are much worse than those without a bogus vortex. Based on several typhoon control experiments, Zou and Qingnong (2000) and Wu et al. (2001) conclude that 4DVAR is effective to modulate initial conditions favor- 
able for a sustainable and consistent typhoon evolution. For a mesoscale convective system, Zou and Kuo (1996) also demonstrate that the increased effectiveness and dynamical consistency of 4DVAR actually come from the observation data (rainfall and PW) continuously being ingested in the assimilation time window. In contrast, 3DVAR only deals with the current analyses (both observations and first guesses) and theoretically should be less effective for modulating a dynamically consistent vortex without sufficient ad hoc information. Hence, it is important for 3DVAR to work with a good vortex-bogussing scheme. It will be interesting to see how 3DVAR will modulate environmental conditions with different bogussed vortices and what kinds of combinations of possibly involved parameters will produce better model simulations. This work should be done in a future study with available observations (e. g. QuikSCAT wind and SSM/I retrieved information) over oceanic regions.

Acknowledgments Discussions with Dr. F. Vandenberghe at NCAR and Dr. Y.-L. Lin at NCSU were helpful for this study. Critical comments of two anonymous reviewers have also greatly improved this paper. This study is supported by National Science Council in Taiwan under projects Grant NSC 90-2111-M-008-039-AGC, Grant NSC 90-2111-M-008-040-AGC and Grant NSC 91-2111-M-008-023, and by National Space Program Office under the project Grant NSC90-NSPO(B)-RS3-FA07-01.

\section{REFERENCES}

Anthes, R. A., 1982: Tropical Cyclones: Their Evolution, Structure, and Effects. Meteor. Monogr., 19(41), American Meteorological Society, Boston, 208 pp.

Chen, S.-H., F. Vandenberghe, G. W. Petty, and J. F. Bresch, 2002: Application of SSM/I satellite data to a hurricane simulation. Submitted to Q. J. R. Meteor. Soc., in revision.

Courtier, P., E. Anderson, W. Heckley, J. Pailleux, D. Vasiljevic, M. Hamrud, A. Hollingworth, F. Rabier, and M. Fischer, 1998: The ECMWF implementation of three dimensional variational (3DVAR) data assimilation. Part I: Formulation. Q. J. R. Meteor. Soc., 123, $1-26$.

Dudhia, J., 1993: A nonhydrostatic version of the Penn State-NCAR mesoscale model: Validation tests and simulation of an Atlantic cyclone and cold front. Mon. Wea. Rev., 121, 1493-1513.

Gelb, A., 1980: Applied Optimal Estimation. The M. I. T. press, Cambridge, MA.

Hollingworth, A., and P. Loennberg, 1986: The statistical structure of short range forecast errors as determined from radiosonde data. Part I. The wind field. Tellus, 38A, 111136.

Loennberg, P., and A. Hollingworth, 1986: The statistical structure of short range forecast errors as determined from radiosonde data. Part II. The covariance of height and wind error. Tellus, 38A, 137-161.

Huang, C.-Y., and Y.-L. Lin, 1997: The evolution of mesoscale vortex impinging on symmetric topography. Proc. Natl. Sci. Counc., 21, 285-309.

Lin, Y.-L, D. B. Ensley, S. Chiao, and C.-Y. Huang, 2002: Orographic influences on rainfall and track deflection associated with the passage of a tropical cyclone. Mon. Wea. Rev., 
in press.

Lorenc, A. C., 1992: Iterative analysis using covariance functions and filters. Q.J. R. Meteorol. Soc., 118, 569-591.

Parish, D., and J. Derber, 1992: The National Meteorological Center Spectral Statistical Interpolation analysis. Mon. Wea. Rev., 120, 1747-1763.

Rabier, F., A. Mc Nally, E. Anderson, P. Courtier, P. Unden, J. Eyre, A. Hollingworth, and F. Bouttier, 1997: The ECMWF implementation of three dimensional variational (3DVar) data assimilation. Part II: Structure function. Q. J. R. Meteorol. Soc., 123, 27-52.

Vandenberghe, F., and Y.-H. Kuo, 1999: Introduction to the MM5 3DVAR Data Assimilation System: Theoretical Basis. NCAR/MMM documents, $38 \mathrm{pp}$.

Wu, C.-C., K.-H. Chou, Y.-H. Kuo, and W.-P. Huang, 2001: Observing-systems simulation experiments for tropical cyclone initialization based on four-dimensional variational data assimilation. Proceedings of Conference on Weather Analysis and Forecasting, Central Weather Bureau, Taipei, 29-34.

Zou, X., and Y.-H. Kuo, 1996: Rainfall assimilation through an optimal control of initial and boundary conditions in a limited-area mesoscale model. Mon. Wea. Rev., 124, 28592882.

Zou, X., F. Vandenberghe, M. Pondeca, and Y.-H. Kuo, 1997: Introduction the Adjoint Techniques and the MM5 Adjoint Modeling System. NCAR Technical note, NCAR/TN435-STR, available from NCAR.

Zou, X., and X. Qingnong, 2000: Studies on the initialization and simulation of a mature hurricane using a variational bogus data assimilation scheme. J. Atmos. Sci., 57, 836860. 